\title{
Inquiry into the Cultural Impact on Cost Accounting Systems (CAS) in Sri Lanka
}

\begin{abstract}
Purpose: The purpose of this paper is to critically explore the implementation of Cost Accounting Systems (CAS) using Content Analysis (CA). In particular, it aims to examine the impact of Sri Lankan cultural and local characteristics on the adoption of CAS. In particular, it examines the factors that facilitate or hinder the adoption of CAS in Sri Lanka.

Design/methodology/approach: Primary data for the research was obtained by interviewing selected respondents from Sri Lanka's manufacturing and service sectors. They were shortlisted using Maximum Variation Sampling (MVS) to obtain a representative cross-section of the national population. A total of 16 respondents were interviewed, which resulted in 57 interview paragraphs to be coded. Several theories were employed to analyse them, namely the theory of institutional isomorphism (homogeneity) and the theory of heterogeneity, as well as Clifford Geertz's cultural theories.
\end{abstract}

Findings: A cross-comparison between the findings and relevant literature indicates the existence of complete institutional isomorphism and partial institutional heterogeneity in Sri Lanka. Heterogeneity exists in organisations such as foreign multinationals, which have adopted unique and sophisticated CAS. In addition, inadequate access to information and the orientation of the local culture has affected the implementation of CAS in Sri Lanka, with a lack of awareness of the importance of CAS, a sluggish approach to costing, and cultural values forming prominent barriers to its implementation. These findings are plausible in light of the relationship between a sluggish approach towards costing (a low cost awareness), and local attitudes towards the implementation of more efficient accounting practices such as CAS.

Practical implications: This research is invaluable as a tool for Sri Lankan policy makers and practitioners, enabling the public and private sectors to provide education and training to enhance staff understanding and promote a positive attitude towards costing. With more efficient institutional CAS, the country's economy will be more competitive internationally. As well as policy makers and practitioners, this research could be employed by academicians for advancing theoretical development around the cultural triggers and barriers for adopting more innovative and fresher CAS in Sri Lanka.

Originality/value: The originality of this research can be justified on two counts. Firstly, although a wealth of research exists that examines the influence of culture on behaviour, this research specifically evaluates the impact of cultural factors on attitudes towards costing. These factors could be facilitators or obstructions for implementing CAS. Secondly, this research aims to combine both earlier and recent theories of institutionalism with Clifford Geertz's cultural theory, to investigate how people and institutions in Sri Lanka adopt CAS. Earlier studies have focused merely on earlier theories of institutional homogeneity.

\section{Keywords:}

Sri Lanka, Cost Accounting Systems, Institutional Isomorphism Institutional Homogeneity, Institutional Heterogeneity, Geertz Cultural Theory

\section{Introduction}


A cost accounting system is defined as a systematic framework used by a firm to estimate the cost of their products for measuring their profitability (Drury, 2015; Bragg, 2001; Obara and Ukpai, 2001; Romney and Steinbart, 2011; Martin, 2014). As indicated in the interviews, in this study, cost accounting systems (CAS) include the simple cost of goods sold and an inventory valuation, a breakeven analysis, a full and variable costing analysis, variance analysis (VA) and activity-based costing (ABC). Relevant literature (Evans and Bellamy, 1995; Lucey, 1996; Upchurch 2002; Anthony and Govindarajan, 2004; Lucey, 2008) emphasise that a CAS can serve as an invaluable database for understanding the full cost of resources used. Research (Hansen et al., 2009; Kwan, 2011) indicates that companies which efficiently use CAS outperform, in terms of their global competiveness, those which do not.

This paper explores how cultures and local characteristics have influenced CAS. Specifically, it follows current discourses in the literature (Nagirikandalage and Binsardi, 2015; Nagendrakumar et al., 2015; Yapa and Ukwatte 2015; Adhikari et al., 2013; Adhikari and Mellemvik, 2010; Subasinghe and Fonseka, 2009) concerning accounting changes and reforms in Sri Lanka. However, regarding cultural changes, studies by Lyn and Yu (2002) indicate that resistance to organisational changes has not been an issue for successful CAS implementation. That said, most of the earlier studies have been carried out in the manufacturing industry within a developed country context (Ismail and King, 2005; Al-Eqab and Ismail, 2011) and therefore, the findings may not be applicable in a developing country context. For example, if a developing country such as Sri Lanka is to adopt a developed country's systems, the implementation of CAS may not be, arguably, optimal because a developing country such as Sri Lanka has less developed infrastructure such as a lower accounting literacy rate, inadequate costing systems, traditional processing, less advanced technology, poor infrastructure, low adoption of IT, economic imperfections and other social, political and cultural differentials (Lyn and Yu, 2002; Carvalho et al., 2012).

In addition, the markets in developing countries are structurally different and comparatively smaller than those in developed countries, where most of the earlier studies have been carried out. Sri Lanka, for example, has been characterised, by ad hoc changes in industrial policies, as a result of changes in governments that swing between the two major political parties with their different political ideologies (Attygalle, 2012). This phenomenon has, in turn, led the country to remain unstable, in terms of maintaining consistency in accounting and economic systems, over the past few decades. Moreover, the economy has been overshadowed by a civil war which lasted for nearly three decades. This phenomenon has affected the country's information infrastructure and systems in relation to the Post-Conflict Development Challenge (Destradi, 2010; Athukorala and Jayasuriya, 2012). Besides the fact that these above differential factors can impact the entire scenario of CAS in Sri Lanka, earlier studies on CAS in developing countries are rare in the literature (Lyn and Yu, 2002), and most research on developing countries concentrates solely on financial accounting (Jaggi, 1973; Samuels, 1990; Wallace, 1990; Rahaman et al., 1997; Hopper et al., 2009).

Hence, one aspect of the originality of this paper is that it focuses on the application of CAS in a developing economy in the context of Sri Lanka. Earlier studies (Boulding, 1988; Gray, 1988) had revealed that the cultures of developing economies are different from those of developed or advanced economies in terms of the differences in per capita income, in the degree of industrialisation, in the society's attitudes and behaviours and in the standards of living of economic agents. All of these considerations affect the application of CAS in a particular economy. Because of these differences, economic agents in developing economies tend to 
follow different accounting systems than do those in developed or advanced economies.

Moreover, there are additional justifications for selecting the country as a focus in this research. Sri Lanka promotes more development economics and regional integration in comparison to other South Asian Association for Regional Cooperation (SAARC) countries. In addition, the Colombo Stock Exchange was reported to have the highest growth in the world in 2003, and Sri Lanka was also classified as a country with the highest per capita income in South Asia (Zaheer, 2013). SAARC's member states include Afghanistan, Bangladesh, Bhutan, India, Nepal, the Maldives, Pakistan and Sri Lanka itself. In particular, Sri Lanka's long-lasting civil war ended in 2009, and further research is required to understand its post-war status. This in turn will benefit all SAARC nations in terms of integration of their accounting systems. In addition, Sri Lanka comprises many ethnicities, languages and religions. This cultural diversity provides a challenging research agenda, which could facilitate further trade relations and economic integrations within the SAARC region, in the face of cultural resistance, according to the relevant literature (Weerakoon and Perera, 2014; Kugiel et al., 2013). Most of the earlier literature focuses on the individual aspects that trigger accounting reforms, using the theories of institutional isomorphism (Meyer and Rowan, 1977; Carpenter and Feroz, 2001; Hyndman and Connolly, 2011; Adhikari et al., 2013) and institutional heterogeneity (Läpple, 2015; Naranjo-Gil and Hartman, 2008; Finkelstein and Hambrick, 1996; Golden and Zajac, 2001; Jarzabkowski and Searle, 2005). However, there are no studies that investigate both the triggers and barriers for the implementation of CAS, applying institutional theories and Geertz's cultural theory to real-life situations. Consequently, the aim is to fill a gap in the existing literature, for the purposes of theoretical development.

This is the rationale for undertaking this research. There seems to be an imminent need to investigate the impact of culture on the implementation of CAS in Sri Lanka (Fonseka, et al, 2005). Over the years, institutions and companies in Sri Lanka have been reforming the country's CAS towards more innovative and efficient accounting systems (Nagirikandalage and Binsardi, 2015; Nagendrakumar et al., 2015; Yapa and Ukwatte 2015; Adhikari et al., 2013).

The adoption of new CAS in Sri Lanka can be illustrated by using the institutional theories, such as institutional isomorphism and institutional heterogeneity. These theories can be categorised as triggers, which facilitate the adoption of newer CAS in the country. Contrastingly, the earlier literature (Nobes, 1983; Violet, 1983; Gray, 1988) also indicates that, despite the triggers, there have also been some barriers, which prevent the use of newer CAS in Sri Lanka because of cultural resistance (Nagirikandalage and Binsardi, 2015). Consequently, apart from the two institutional theories, Clifford Geertz's cultural theory of cultural resistance will also be presented to examine the barriers to CAS adoption (Figure 1).

Since the theories (Figure 1) were selected because they function as rationalistic explanations of institutional and individual behaviour toward the adoption of new CAS - which are embedded in the larger cultural and political domain - they encompass a range of theoretical frameworks around the central research question of "What is the impact of cultures on the adoption of CAS in Sri Lanka?" Following this central research question, several research objectives were formulated accordingly, as follows: (1) to gauge the dynamics involved in the process of promoting and hindering the adoption of CAS within the manufacturing and service sectors in Sri Lanka; (2) to analyse the detailed reasons for the lack of usage of CAS in Sri Lanka; and (3) to identify the application of institutional homogeneity and institutional heterogeneity in Sri Lanka in relation to the adoption of more modernised CAS. 
Figure 1 - Theoretical Framework

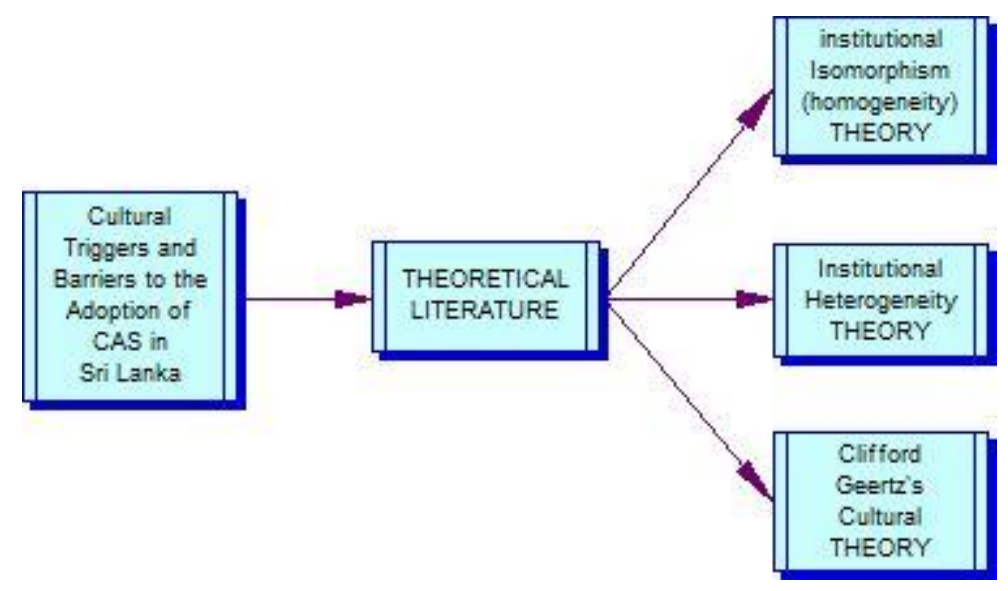

This paper is divided into five sections. Section 1 provides an introduction, including the background and rationale for the study. Section 2 covers the theoretical perspectives of the usage of CAS in Sri Lanka and the theories of cultural and institutional isomorphism such as the earlier theories of homogeneous isomorphism and the more recent theories of heterogeneity. Section 3 discusses research methodology to achieve the research objectives, which involves data collection, a sampling strategy, data analysis and the limitations of the study. Section 4 offers the results and section 5 concludes with a brief summary, along with recommendations for further research.

\section{Literature Review}

\subsection{The Institutional Theories}

Earlier institutional theories of institutional isomorphism or institutional homogeneity, and the more recent theory of institutional heterogeneity, can be employed to explain the adoption of CAS in Sri Lanka. Homogeneous isomorphism has been employed for conceptualising changes in organisations (Ashworth et al., 2009; Poole and van de Ven, 2004; Dacin et al., 2002; Greenwood and Hinings, 1996; DiMaggio and Powell, 1991). These changes include reforms from traditional organisational rules, routines and systems towards more innovative and newer accounting systems (Burns and Scapens, 2000).

In brief, the spirit of isomorphism aims to enhance organisational performance such that when organisations become recognised entities within an industry, other organisations will attempt to adopt similar best practices in order to achieve similar competitive advantage. Institutional isomorphism theory explains organisations' survival through the continuous adoption of legitimised structures as discussed individually below.

Firstly, the initial institutional isomorphism theory is known as mimetic isomorphism. By quoting the work of Hawley (1968), DiMaggio and Powell (1983) have described mimetic isomorphism as a "coercing" process that encourages one entity to resemble the others in the 
population that face the same set of environmental pressures. Secondly, normative isomorphism mainly derives from professionalisation, which is a collective struggle of associates of an occupation to define the conditions and methods of their work, in terms of controlling occupational autonomy (DiMaggio and Powell (1983), who have quoted the works of Larson (1977), and Collins (1979)). Hence, the mechanism for encouraging normative isomorphism is to filter personnel via the hiring of qualified individuals from organisations within the same industry. For example, high skill level requirements and promotional practices exist, especially when hiring top-level executives. Thirdly, coercive isomorphism involves the outcome of both formal and informal pressures applied on 'lower'-level organisations by other organisations because of the aspects of cultural dependency and expectations within the society.

The earlier institutional homogeneity theorists argue that organisations facing similar institutional pressures due to strong environmental influences will eventually adopt similar strategies. Hence, by being embedded in society (Westney, 1993), organisations operating in a country, including the multinational corporations are influenced by their stakeholders, including the governments through regulations, the industry through standards and norms, the competitors through better business strategies and the consumers through loyalty (Freeman, 1984; Clarkson, 1995). Furthermore, not only do forces based on competition and efficiency act upon the organisation, but socially constructed beliefs and systems of rules also exert considerable control over organisations (Popadiuk et al., 2014) such as the culture of the society as well. However, Waldron (2005) identified barriers to change regarding the adoption of CAS in different organisational settings, which implies that although, costing systems have changed significantly over the past 100 years because of continuous technological and competitive change in today's global environment (Boyns and Edwards (1997), not all organisations have adopted CAS as an organisational strategy.

In reality, not all organisations have adopted homogeneous CAS because this adoption also depends on social and institutional practice as well as the degree of competition with their rivals (Miller, 1994; Scapens, 1994; Humphrey and Scapens, 1996; Burns and Scapens, 2000; Chapman et al., 2009). Organisations strive to achieve what their competitors have obtained or at least match them, owing to uncertainty created by obsolete technology, recession, etc. Homogeneous isomorphism theory aims to enhance organisational performance, so that when organisations become recognised entities within an industry, other organisations will attempt to adopt similar best practices in order to achieve similar competitive advantages. In order to beat competition, organisations must enhance their performance. Furthermore, the theory suggests organisations adopt new rules, codes of conduct, and systems such as CAS, depending on the environment around them. These rules and codes represent the set of values and norms that govern the behaviour of the population within these organisations (Senaratne and Gunarathne, 2010). Moreover, modern environmental pressures such as sustainability and development have induced changes in organisational settings that require strategic adaptation to avoid compromising corporations' business objectives (Escobar and Vredenburg, 2010).

Institutional isomorphism (homogeneity) has been widely used to compare homogeneity of structures and systems between businesses as a result of imitative development. That is, in order to be more competitive and survive, companies must follow and imitate higher-level multinational companies by aiming for similar, homogeneous systems and structures. However, recent studies have not fully identified homogeneity, instead showing multiple and heterogeneous logics (Friedland and Alford, 1991; Lounsbury, 2007) in which organisations successfully create a barrier to imitation or 'isolating mechanisms' in terms of their superior systems and structures, which are protected in their property rights (Hooley and Greenlay, 
2005; Winter, 2003). This reinforces superior organisational identities (Thornton, 2002) and leads, alternatively, to the resource-based view (RBV) of organisations where resources such as finance and technology allow some to implement strategies to adopt and customise systems such as CAS individually. Hence, organisations' specific systems and capabilities are rare, valuable, and difficult to copy. Such capabilities increase as a result of the collection of strategic decisions made in the face of competition (Dierickx and Cool, 1989; Pettus, 2001). Moreover, this heterogeneity expects organisations to differ in the capabilities they control, further explaining the competitive advantage some enjoy.

Relevant literature (Gordon and Miller, 1976; Gupta et al., 1994; Geiger and Ittner, 1996) suggests that the adoption of individual CAS depends on company environment, organisational structure, technology, and decision-making styles, as well as organisational performance. This reinforces the more recent theory of heterogeneity. Hence, the RBV cannot be explained with a simple institutional homogeneity theory due to the fundamental premise that competitive disparities are the result of capabilities heterogeneity at the organisational level within an industry (Barney, 2002; Wernerfelt, 1984). Lastly, according to the RBV, organisations can obtain sustained abnormal returns if they own superior systems and are protected by mechanisms that prevent their diffusion throughout the industry (Popadiuk et al., 2014). Therefore, the concept of competitive advantage can be related directly to the view of profits in excess of the opportunity cost of capital, a persistently higher rate of return than competitors, and when the value system is not implemented by current or potential competitors and its benefits cannot be duplicated by others (Barney, 1986, 1991; Hamel and Prahalad, 1994; Lippman and Rumelt, 1982; Penrose, 1959; Peteraf, 1993; Rumelt, 1984; Wernerfelt, 1984).

Furthermore, relevant literature (Penrose, 1959; Wernerfelt, 1984) examines organisations as sets of resources, where competitive advantage is generated through the maintenance of RBV position and resources are considered heterogeneous. However, an organisation has competitive advantage when competitors are incapable of duplicating the benefits of this strategy, plus not all organisational resources generate sustainable competitive advantage. Moreover, employment of a resource that is socially complex, such as culture or reputation towards suppliers and customers (Barney, 1991) would affect the organisation's strategy and systems such as CAS. Additionally, superior resources remain limited and most can be sold in imperfect markets of strategic factors. Hence, some assets, such as relationships between an organisation and its suppliers and customers, need to be accumulated internally (Popadiuk et al., 2014). However, due to inherent mobility these marketable resources do not constitute sustained competitive advantage (Basso, Meirelles and Pace, 2005; Dierickx and Cool, 1989; Ginsberg, 1990; Peteraf, 1993). Therefore, the RBV's assumption that strategic resources are created by consistent policies and accumulated internally implies the role of institutionalisation towards organisational heterogeneity from intangible and non-tradable resources (Popadiuk et al., 2014).

Apart from the RBV's assumption, cultural expectations, alongside institution and competition, have played a major role in influencing organisational strategies and systems as per aspects of heterogeneity and homogeneity. 'Cultures' have been identified as essential components for accommodating changes in social systems, since social systems themselves influence the norms and values of group or individual behaviour within an industry (Geertz, 1973). This organisational heterogeneity impacts upon the systems themselves in turn. Moreover, this tautology implies that cultures have a direct impact on isomorphism with regards to homogeneity as well. For example, since one country's legal system could be different from another's due to cultural differences; the degree of coercive isomorphism between these 
countries could be dissimilar. Furthermore, isomorphism occurs in organisational fields and provides a context where individual efforts to rationally deal with uncertainty and constraint lead to superior homogeneity in structure, culture, and output (Popadiuk et al., 2014).

\subsection{The Cultural Theories}

Several prominent studies investigate the relationship between national cultures and accounting in general, such as Cieslewicz (2014), Iraj, et al. (2007) and Prescott and Vann (2015), using theoretical frameworks outlined by Gray (1988), Geertz (1973), and Hofstede (1991, 1984). Prescott and Vann (2015) investigate the effect of national cultures on financial statement comparability following Gray's framework (1988), and extending Hofstede's cultural framework $(1991,1984)$. They suggest that significant international differences in corporate financial reporting systems could be due to a society's values impacting the development of national accounting standards and financial reporting, thus CAS. Cieslewicz (2014), Iraj, et al. (2007), and Prescott and Vann (2015) use a theoretical framework based on cultural theories, rather than empirical accounting theories. Such theories stand in isolation from the empirical key themes, as these types of studies, in addition to this paper, are multidisciplinary in nature. By definition, multidisciplinary research must 'borrow' theories that are outside the remit of a specific subject area.

Geertz's cultural theory (Geertz, 1973; Burke, 1997; McCloskey, 1988; Arnould and Thompson, 2005; Hoffman, 2001; Alexander et al., 2011) provides an appreciation of 'thick description' of cultural reality. Social anthropologists have used the term 'thick description' widely to explain the cultural perception and behaviour of a shared community through contextual understanding, to the extent that the cultural behaviour becomes meaningful and understandable to outsiders. The cultural perception and behaviour is semiotic in terms of processes, designation, likeness, analogy, metaphor, symbolism, signification, and communication. This semiotic aspect of cultures affects organisational systems, for example, in the way a company's costs can be communicated and processed to management through CAS, such as absorption costing, full costing, activity-based costing (ABC), etc. Accordingly, Geertz's theory has implications for explaining the impact of cultures on CAS. Geertz further argues that to interpret cultural impact, the internal relationships among systems should be examined as well as underlying structures and people. Geertz's work influenced early works on the influence of 'group cultures' on accounting systems (Nobes, 1983; Violet, 1983; Gray, 1988). They reveal group cultural values could infiltrate organisational subcultures, which in turn could either facilitate or obstruct the adoption of newer CAS.

Furthermore, Nobes (1983) introduced a Judgmental Classification Scheme showing the direction from which accounting systems originate. As Sri Lanka was once a British colony, it is classified inside the cluster of 'Full Disclosure'. Within this cluster, accounting systems are orientated towards the needs of large numbers of investors and creditors. Correspondingly, Sri Lanka can be classified as belonging in Cluster 1, which shares common CAS and orientation with other countries such as the United Kingdom, Ireland, Malaysia, Hong Kong, Jamaica, Luxemburg, Netherlands, Namibia, Philippines, Papua New Guinea, Nigeria, New Zealand, South Africa, Taiwan, Trinidad and Tobago, Zambia, Zimbabwe and Singapore. However, there are slight complications, because the classification consists of several countries, which have different national cultures as well as dissimilar economic development.

National cultures can be defined here as the collective mental programming of the human mind, which distinguishes one country from another (Hofstede, 1991, 1984). This collective mental 
programming influences people's perception and behaviour, which in turn is reflected in the meaning people attach to various aspects of life, including their attitude towards costing. Hofstede $(1991,1984)$ further added that Sri Lanka is a hierarchical and collective society, which is also known in the literature as 'vertical collectivism'. In comparing it to a more developed country such as the UK, Britain can be classified as an individualist society, in which people behave more individually and care for themselves egoistically, as opposed to having a collective outlook. By contrast, in collectivist societies such as Sri Lanka, Pakistan, Costa Rica, Taiwan and South Korea, people have a sense of cooperative responsibility towards larger groups and extended families, taking care of the overall group in exchange for group loyalty.

Consequently, Sri Lanka and the UK can both be classified in Cluster 1 of 'Full Disclosure' in terms of their accounting systems. But because Sri Lanka and the UK differ considerably in their national cultures, people's attitudes and perceptions towards costing differ considerably. For example, recent accounting reforms in both countries have arguably differed in terms of their final CAS adoption outcomes. This attitudinal and perceptive differentiation between Sri Lanka and the UK materialises because of the interaction between their separate national cultures and different economic development. In fact, the UK is considered a developed or advanced country, while Sri Lanka is still classified as a developing country, according to the World Bank (2015). Hence, it seems more logical that the UK has a more optimistic attitude towards costing for facilitating the adoption of more modernised CAS in line with the needs of its level of economic development. More advanced economies, such as the UK, USA, etc., require the adoption of newer $\mathrm{CAS}$, such as $\mathrm{ABC}$, because more sophisticated CAS are required to compete successfully among multinationals in a highly competitive environment in the global markets.

In summary, institutional isomorphism theorists of homogeneity aim to develop a sociological view of organisations to explain why so many businesses end up having similar advanced systems. They do this by observing institutions outside of traditional economic views (Meyer, 1979; Fennell, 1980; DiMaggio and Powell, 1983). However, with regards to recent organisational development, RBV theory (Mahoney and Pandian, 1992; Smith and Rupp, 2002; Hooley and Greenley, 2005) has been widely employed to explain why so many businesses have different systems ('heterogeneity') in contrast to earlier theories of homogeneous isomorphism. Furthermore, RBV theory reveals a company's ability to deliver sustainable competitive advantage when its resources are managed such that their structures and systems cannot be impersonated by competitors - due to rarity, inimitableness, non-substitutableness, and firm specificity (Barney, 1999; Finney et al., 2005, Makadok, 2001).

This literature review (Section 2.1) discusses early institutional theories of homogeneity including mimetic, coercive, and normative isomorphism. More recent theories of heterogeneity and practice variations were also examined in order to analyse the impact of cultures and local characteristics on CAS. This section also looked at another cultural theory to provide a refreshed theoretical basis for approaching the application of CAS in a Sri Lankan context. Earlier anthropological literature considers cultures as a collection of traits with certain meanings in the context of evolutionary stages influencing social institutions and local systems. Furthermore, relevant literature (Geertz, 1973; Alexander et al., 2011) on symbolic anthropology looks at how people's mental constructs guide their daily lives and practices. This can be applied widely, including the application of CAS in particular countries (Nobes, 1983; Violet, 1983; Gray, 1988) as to this study intends to make a significant contribution to the current discourse concerning accounting reforms in Sri Lanka. 


\section{Research Methodology}

\subsection{Data Collection and Sampling Issues}

Qualitative research methodology was employed in this study by selecting the respondents purposefully. It is not questionable that CAS in Sri Lanka as a whole could be captured in this study, since this study is an inquiry to explore the application of, triggers and barriers for the implementation of CAS in Sri Lanka by using a qualitative research methodology. The qualitative research methodology aims at exploring a research phenomenon to uncover trends in deeper thought and to dive deeper into the cultural problems, if any, related to the application of CAS for the purposes of gaining an initial understanding of underlying reasons and motivations.

This paper employs both directed and summative content analyses by utilising a priori theory (Geertz, 1973; DiMaggio and Powell, 1983; Hofstede, 1984; 1991; Gray, 1988; Morgan et al., 2010) to guide the themes used in the interviews, as indicated in Figure 2. In this study, an indepth interview technique was employed in order to provide a deeper understanding of cultural phenomena than would be obtained from quantitative methodology such as survey questionnaires. The reason for employing the technique is that it involves face-to-face contact and avoids misunderstanding, as the investigator has an opportunity to clarify questions as well as validate the answers relating to various aspects of CAS adoption in Sri Lanka. Moreover, the investigator can explore the topic in depth by discussing it in more detail. This technique proved to be successful since it provided richer qualitative data than expected as the respondents produced new insights into the aspects of CAS adoption, which was useful for the research. The selected respondents for primary data originated from the service and manufacturing sectors (Table 1). Apart from the variation by sector, the respondents came from a variety of companies and institutions, namely banking and finance, construction, hospitality, telecommunications, education, and manufacturing, such as garments, tyres, teas and foods (Table 2). Correspondingly, the following table 1 including the interview schedule provides detailed information on the time spent by the investigator with each interviewee in Sri Lanka during the period January-March 2012. On average, each interview took 126 minutes. The time includes the initial introduction to the issues of CAS adoption in Sri Lanka, the coverage of anonymity, confidentiality and the ethical issues of the research, the explanation of what constitutes CAS, another explanation of the link between CAS and the managerial process and the explanation of what constitutes cultural triggers and barriers.

Table 1 - Respondents and Time spent for Interviews

\begin{tabular}{|l|l|l|}
\hline Sector & Number of respondents & Time spent (minutes) \\
\hline Service & 7 & 876 \\
\hline Manufacturing & 9 & 1140 \\
\hline Total samples & 16 & 2016 \\
\hline
\end{tabular}

The majority of the respondents were from the lower, middle or higher management levels of the selected institutions. In addition, in order to fulfil the criteria for theoretical sampling, they were fully familiar with CAS in Sri Lanka; in other words they needed to be knowledgeable of the subject under investigation in order to come to valid conclusions and thereby provide credibility. However, this study employed a relatively small number of samples following qualitative investigation (phenomenology paradigm), and because of this methodological 
constraint, the final findings are restricted in terms of the ability to make further generalisations to the wider population or other countries. The samples in the qualitative research methodology are relatively small and do not intend to represent the whole population (Denzin 1988; Patton, 2001). Qualitative research methodology aims to produce an initial inquiry to gain a deeper comprehension of underlying cultural reasons and motivations to develop potential hypotheses to be researched by using quantitative research at a later date.

In qualitative investigation, purposive (non-random) sampling is a commonly used technique, in which the number of samples interviewed is less important than the criteria used to select them (Ritchie and Lewis, 2003; Glasser and Strauss, 1967). This methodological limitation or imperfection is also known in the literature as 'limited external validity' (Carmines and Zeller, 1979; Carmines and McIver, 1981). Although the samples consist of only 16 respondents from two sectors this study has employed the maximum variation sampling (MVS) technique by optimising the diversity of the respondents across both sectors, and by including this range of extremes, the aggregate findings are expected to be close to the whole population's mean (Coyne, 1997; Creswell, 1998).

Although there is relatively high ownership concentration in Sri Lanka and high diversity in the service sector, this will not have a bearing on this study as the study has implemented MVS to optimise sampling diversity in qualitative research methodology (Coyne, 1997; Patton, 2001) where the samples are expected variably to represent a wide range in CAS across sectors and demographics. This variation is expected to reflect the diversity of attitudes and opinions, counterbalancing the lack of wider generalisation and population representativeness (LewisBeck et al., 2004; Patton, 1980). Furthermore, although there is a possibility that several respondents belong to few sectors, this will not change the outcome of the study. Using qualitative research methodology, this study aims at exploring an initial understanding of the phenomena of cultural barriers and triggers of CAS application in Sri Lanka by using MVS so that the understanding of CAS of a variety of respondents can be determined across different managerial levels.

Apart from the samples variation, additional measures were taken to improve credibility. Firstly, the data gathering was conducted using a specific filtering procedure, in which each participant was given opportunities to withdraw from participation at any time without giving a reason, to ensure that the data collection involved only those respondents who were genuinely interested in taking part in the research. This action helped ensure participants' willingness and honesty. Secondly, at the start of the interviews, the participants were encouraged to build a positive rapport with the researchers. For example, they were told there were no right or wrong answers to the questions. Thirdly, the independent status and anonymity of the respondents were emphasised. This encouraged the participants to feel open to discuss their experiences without any fear of losing credibility in their organisation. Fourthly, a preventative strategy was employed. This involved triangulating iterative questions to minimise and uncover unreliable and contradictory answers during the interview. Fifthly, a probing approach was implemented by rephrasing the interview questions. This approach was successful in detecting non-credible and contradictory data. Lastly, frequent debriefing sessions were carried out with the respondents' superior or Chief Executive Officers of the institutions involved, which contributed to an optimal data collection.

The first author visited Sri Lanka during the period of December 2013 to March 2014 and spent four months conducting in-depth face-to-face interviews with the selected respondents. Potential respondents had initially been contacted in advance of the researcher's visit in 
December 2013 via telephone and email. Appointments were made with those who were interested in participating in the research. Because some of the respondents were busy professionals, their work schedules necessitated some cancellations and rearrangements. All the interviews and data collection were carried out in four months.

\subsection{Data Analysis}

Content Analysis is used to analyse the primary data. It is a qualitative research method for systematically interpreting the content of communicated or interview paragraphs. This research employs directed and summative Content Analysis, followed by an interpretation of the underlying cultural context. Directed Content Analysis was employed by utilising earlier literature including, inter alia, studies by Alexander et al. (2011), Collins, (1979), DiMaggio and Powell (1983), Geertz (1973), Gray (1988), Hooley and Greenlay (2005) Larson (1977), Nobes (1983), Thornton (2002), Violet (1983) and Winter (2003), which utilise institutional isomorphism, heterogeneity and cultural theories to code the communicated or interview paragraphs. Although Content Analysis can be considered a qualitative method (Hsieh et al., 2005; Lewis-Beck, Bryman and Futing Liao, 2004), it is also viewed as a quantitative method (Berg and Lune, 2013) because summative Content Analysis uses statistics to count how many particular 'codes', or 'themes' appear in the communicated interview paragraphs.

In this study, in order to examine the consistency of different interview texts, a triangulation technique was used, namely, triangulation of sources. This technique was implemented by examining the consistency of different interviews and comparing one interview with others, which had different viewpoints. Moreover, the consistency of the interview texts was triangulated with the detailed discussion with the company's Chief Executive Officers involving the use of multiple sources in a qualitative investigation to corroborate an accurate understanding. By using the triangulation of sources, it is intended that the limited clarity of one interview text can be validated by other sources for validation or verification purposes (Denzin, 1978; Patton, 1999).

This paper employs both directed and summative content analyses by utilising a priori theory to guide thematic coding processes. Thematic coding is defined here as a technique for revealing patterns within data. It has been adopted in this study to answer the research questions ("what, why and how"), since the data consists of the respondents' experiences and perceptions on CAS. Apart from directed content analysis, summative Content Analysis was also applied where the presence and meanings of the interview paragraphs are quantified to analyse how many times certain important "Keywords-In-Context" or themes appear in relation to the Institutions Isomorphism Theory. This study employs an NVivo software package to carry out both directed and summative content analyses by coding the interview paragraphs into thematic categories, then applying relational analysis inside the codes.

Moreover, directed and summative Content Analyses are the most suitable qualitative methodologies to answer the research questions, since they are inductive approaches which explain people's perception and behaviours in social and cultural environments (Miles and Huberman, 1994; Kvale, 1996; Creswell, 1998; Denzin and Lincoln, 1998; Babbie, 2008). Also, there has not been any empirical paper written on the use of Content Analysis to investigate CAS in Sri Lanka in relation to the Institutional Isomorphism Theory. Accordingly, this paper is useful for guiding further qualitative research in the application of CAS in a developing country context. 
However, due to limited coverage across the service and manufacturing sectors, this research is not suitable for making generalisations that include other sectors. Further research that includes other sectors is suggested in order to broaden the scope of this study. It is expected that further studies may be undertaken using a larger sample size that includes a cross-section of small, medium and large enterprises, so as appropriate policy implications can be derived accordingly.

\section{Results and Discussion}

These findings of this research were based on primary data, which were collected thorough face-to-face (in-depth) interviews with selected respondents. 16 respondents (57 interview paragraphs) were selected purposefully by using maximum variation sampling (MVS). MVS was used to capture a wide range of issues related to the phenomena of triggers and barriers to adopting the CAS in Sri Lanka.

All of the 16 respondents were male, except for one female. They were aged between 30 and 60 years, except the female accountant, who was 27 years of age. The majority of the respondents resided within the commercial sector (Table 2). Some of them served as Chief Executive Officers (CEOs), Chief Financial Officers (CFOs) and Chief Accountants. All of the respondents had received formal education and had obtained degrees either in accounting, engineering, or science. The majority of respondents were professionally qualified as accountants, for which they obtained professional qualifications from Association of Chartered Certified Accountants (ACCA), Chartered Institute of Management Accountants (CIMA), or Institute of Chartered Accountants Sri Lanka (ICASL).

Table 2 - Respondents' Organisations

\begin{tabular}{|l|l|l|}
\hline Occupation & Organisation & $\begin{array}{l}\text { No of Respond- } \\
\text { ents }\end{array}$ \\
\hline $\begin{array}{l}\text { Chief Executive Of- } \\
\text { ficer }\end{array}$ & $\begin{array}{l}\text { Garment manufacturing com- } \\
\text { pany }\end{array}$ & 1 \\
\hline $\begin{array}{l}\text { Chief Executive Of- } \\
\text { ficer }\end{array}$ & Tyre manufacturing company & 1 \\
\hline $\begin{array}{l}\text { Chief Executive Of- } \\
\text { ficer }\end{array}$ & Tea manufacturing company & 1 \\
\hline $\begin{array}{l}\text { Chief Operating Of- } \\
\text { ficer }\end{array}$ & $\begin{array}{l}\text { Small manufacturing com- } \\
\text { pany }\end{array}$ & 1 \\
\hline Director of Finance & Leading Banks & 2 \\
\hline $\begin{array}{l}\text { Chief Executive Of- } \\
\text { ficer }\end{array}$ & Construction company & 1 \\
\hline Director of Finance & $\begin{array}{l}\text { Garment manufacturing com- } \\
\text { pany }\end{array}$ & 1 \\
\hline Chief Accountant & Telecommunication company & 1 \\
\hline General Manager & Tyre manufacturing company & 1 \\
\hline Chief Accountant & $\begin{array}{l}\text { Garment manufacturing com- } \\
\text { pany }\end{array}$ & 1 \\
\hline Chief Accountant & Leading hotel & 1 \\
\hline Accountant & $\begin{array}{l}\text { Garment manufacturing com- } \\
\text { pany }\end{array}$ & 1 \\
\hline
\end{tabular}




\begin{tabular}{|l|l|l|}
\hline Accountant & $\begin{array}{l}\text { Small manufacturing com- } \\
\text { pany }\end{array}$ & 1 \\
\hline $\begin{array}{l}\text { Chief Executive Of- } \\
\text { ficer }\end{array}$ & $\begin{array}{l}\text { Leading educational institu- } \\
\text { tion }\end{array}$ & 1 \\
\hline Accountant & $\begin{array}{l}\text { Leading educational institu- } \\
\text { tion }\end{array}$ & 1 \\
\hline Total & & 16 \\
\hline
\end{tabular}

\subsection{Cultural Impact on CAS}

Using 'directed' Content Analysis (Hsieh et al., 2005; Given, 2008; Berg, 2009), the theoretical framework (the institutional isomorphism, institutional heterogeneity and Geertz cultural theories) (Geertz, 1973; Kanter, 1977; Meyer and Rowan, 1977; DiMaggio and Powell, 1983; Hamel and Prahalad, 1994; Hoffman, 2001; Barney, 2002; Arnould and Thompson, 2005; Morgan et al., 2010; Alexander et al., 2011; Popadiuk et al., 2014) were employed to guide the coding process. The findings identified the existence of cultural triggers and barriers to the adoption of CAS in Sri Lanka. The phenomena can be coded diagrammatically into the groups below (Figure 2).

Figure 2 - Codes of Cultural Triggers and Barriers to the adoption of CAS in Sri Lanka

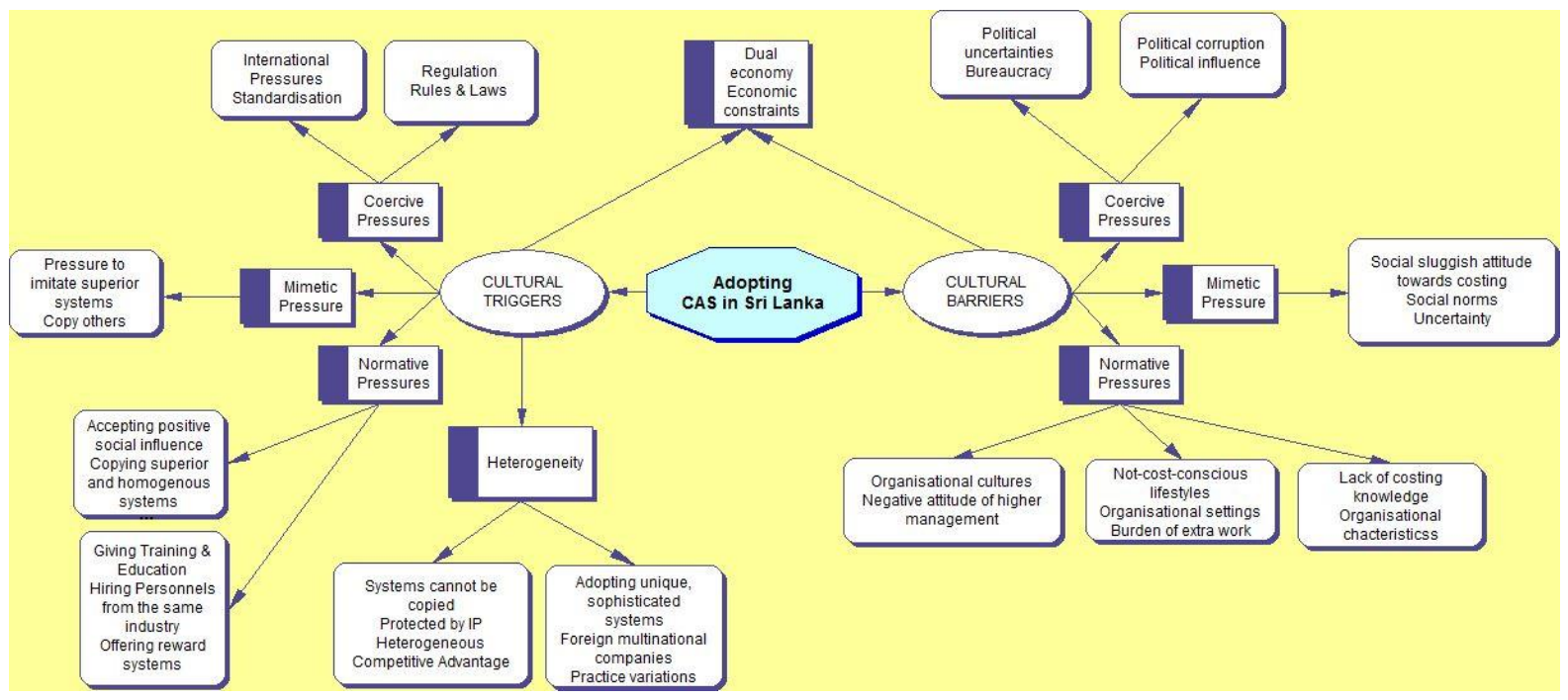

Figure 2 shows the cultural triggers and barriers to the adoption of CAS in Sri Lanka, which were caused by institutional isomorphisms such as coercive, normative, and mimetic pressures as well as institutional heterogeneity and local cultures. This research utilises the concept of institutional isomorphism (Kanter, 1977) instead of competitive isomorphism since the degree of openness of the Sri Lankan macro-economy is not fully competitive compared with those of developed countries, such as the USA and the UK. Accordingly, using the institutional isomorphism theory enables the consideration of performance-conscious pressures on organisations in order to conform to the outside world. This fits very well with the Sri Lankan economy with its growing number of foreign direct investment (FDI) and multinationals those have come into the country.

Further examination of the interview data (no. 1 and 3) indicates that group cultures have been 
identified as dominant barriers to the adoption of CAS. Conversely, group cultures have also influenced coercive pressure, since the Sri Lankan legal systems have themselves been affected by culture. This finding seems to be in line with the earlier literature indicating the relationship between cultures and the adoption of accounting systems in some countries (Nobes, 1983; Violet, 1983; Gray, 1988). Although group cultures do have an impact on attitudes towards costing, a sophisticated explanation is needed here, in parallel with Clifford Geertz's cultural theory of 'thick description'. This is that there are many individuals within subgroups and groups in national cultures, as indicated in Figure 3 below.

Figure 3 - Individual, Sub Group, Group and National Cultures

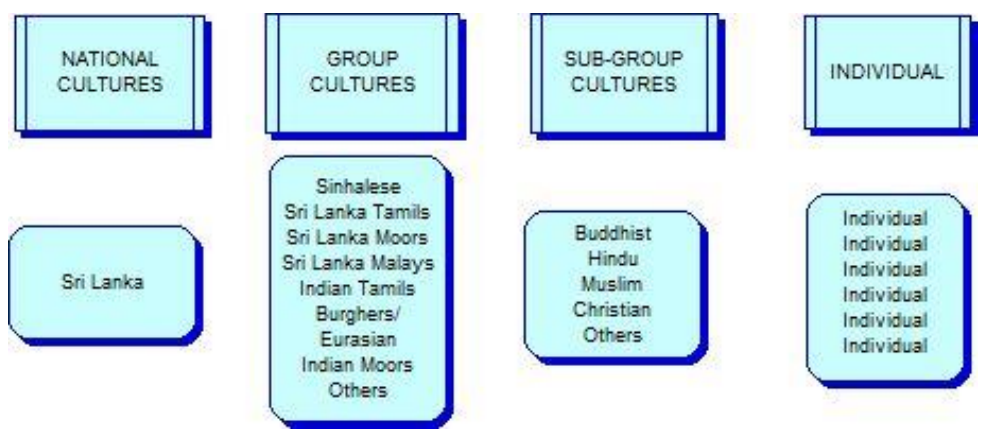

Figure 3 indicates the diagrammatic relationship between individuals, sub-groups, groups and national cultures in Sri Lanka, though every individual in Sri Lanka is unique in terms of their individual behaviour towards costing. The interview texts reveal the similarities among individuals (interview paragraphs no. 1 and 3), where individual attitudes and perceptions are part of sub-group and group cultures, while sub-group and group cultures are part of national cultures.

In this case, the country consists of several ethnic group cultures, from Sinhalese, Tamils and others, whilst sub-group cultures comprise religions such as Buddhism, Muslimism and others. The group cultures form social shared attitudes and perceptions towards costing, as indicated by the interview paragraphs (no. 1,5 and 8), where some respondents across the samples show similar negative perceptions towards costing. These attitudes and perceptions belong to the same group cultures of Sri Lankan people in a parallel manner. However, over-simplistic interpretation of typical patterns of attitude towards costing (say Y) as mere manifestations of Sri Lankan cultures (say X) should be avoided. Hence, we cannot merely say X causes Y. It would be misleading for outsiders, because there are many ethnic groups within the Sri Lankan population, as well as individual attitudes among the respondents (Figure 3). By contrast, some respondents have positive attitudes towards costing (interview paragraphs no. 3 and 13). In particular, those from certain demographics (such as those with a higher level of education and/or employment with multinationals) tend to view costing more optimistically.

Sri Lankan national cultures shape group and sub-group attitudes and perceptions towards costing into cultural resistance to change. National cultures are defined here as the collective mental programming that influences patterns of thinking that people attach to various aspects of life, including their attitudes towards costing. Hence, there are considerable differences among individuals in Sri Lanka, as indicated in the respondents' interview paragraphs. Some particular respondents reveal similarly strong, shared group cultures of negative attitudes toward costing. The thick description explanation is that there have been mixed factors in this 
cultural resistance. Firstly, group cultures' stubbornness emanates from the fact that Sri Lanka is still classified as a developing country (World Bank, 2016), in which a large proportion of people are living just above the poverty line (UNDP, 2012). People living in poverty tend to ignore costing issues because they do not know how to solve the problems of poverty - it is a vicious circle, as indicated by the interview paragraphs (no. 1 and 2).

Although some individuals have a more positive perception towards costing, in general people are loyal to what is the 'common approach' within their group. That is to say, the respondents answered and began by perceiving in accordance with group and common opinion. For example, the interview texts no 1,5 and 8 indicate group shared justifications of negative attitudes towards costing such as 'our people are not geared towards cost', 'we make profits, accordingly the management do not take much consideration of these'. This does not mean that every person in Sri Lanka's national cultures is programmed in a similar way. But though there are individual differences, group cultures of shared opinion tend to be dominant for some respondents in terms of antagonistic attitudes towards costing.

Some respondents identified these group cultural influences as one of their major concerns regarding implementing CAS. In addition, these phenomena have been further exacerbated by the fact that some employers are not sensible to costs in general, as indicated by interview paragraph number 1. Selected interview paragraphs are provided in the Appendix.

As indicated by the interview paragraph (no. 1), some respondents leave costing problems to the male as the head of the household and breadwinner. In Sri Lanka, males head up $75.7 \%$ of households and females only $24.3 \%$ (DCS, 2012). In this male dominant society (patriarchy), all responsibilities and costing issues are left to males as the cultural norm. Patriarchy is a social system in which males hold the primary power in all household issues, including daily costing (Vithanage, 2015). This in turn leads to some negative attitudes towards costing.

Overall, the findings reveal that some organisations in Sri Lanka do not understand the importance of costing. Correspondingly, they have been reluctant to invest and update their systems into more modern CAS (interview paragraphs no. 2 and 12). For example, the themes of 'not cost-conscious' appears several times of the overall interview paragraphs. This finding relates to the Sri Lankan cultural lifestyle, in which people are not cost-oriented or not costconscious, in the sense that the majority are not trained and educated from childhood on budgeting and costing unless they attend accountancy schools. Accordingly, because they are not cost-conscious, they do not consider the implementation of any CAS to be useful at all. This finding relates to Geertz's cultural theory that to interpret the cultural impact on CAS in Sri Lanka, internal relationships between systems, such as duality or a dual economy, should be analysed in addition to underlying structures and people that have influenced the implementation of CAS. In this sense, Sri Lanka can be defined as a 'collectivistic culture', in which people view themselves as connected to others in terms of their attitudes towards costing. Accordingly, there is considerable resistance to change locally; Sri Lankans are reluctant to adopt new CAS due to the level of detail and precision required to implement it, including steps such as Activity Based Costing (ABC) systems, which require the additional labour of undertaking research on cost centres and behaviours. This factor not only affects the manner in which executives manage and shape employee attitudes towards costing, but also the way in which organizations in Sri Lanka processes its products and meets minimum costs.

It is easy to implement CAS if the knowledge on costing comes from both employers and employees. However, since this is not the case, this phenomenon has been identified as a 
cultural barrier because there has been a lack of concern regarding costing from both employers and employees. Accordingly, sluggish attitudes towards cost-related issues in organisations, such as minimising wastage, resisting new systems, and reducing workloads act as barriers to the adoption of CAS. Apart from theses cultural barriers, political inefficiencies and economic uncertainties in the past have also had an influence on organisations in terms of putting new investment into such sophisticated implementations as CAS on hold. Nevertheless, the level of respondents' awareness of CAS and its benefits was equally high amongst all respondents since almost every respondent commented that successful CAS adoption was related to financial and cultural facilitation by their institutions (Interview Paragraphs No. 3). Furthermore, a lack of usage of modern CAS existed in most of the organisations while adapting to older CAS, such as Absorption Costing Methods. That is, most of the respondents indicated that they employed more traditional CAS through the use of Excel and other customised IT software packages. Others employed hybrid CAS by combining ABC methods with local requirements, while the rest of the respondents were in the middle of processing their existing systems into more modern CAS, such as ABC (Interview Paragraphs No. 4, 6 and 13). Additionally, Lucey (1996) mentioned that because of no statutory requirements to maintain detailed cost records, small firms keep only traditional financial accounts and prepare cost information in an ad-hoc fashion, although, the majority of firms maintain cost accounts in some other forms. This ad hoc fashion has been employed not only by smaller organisations but also by medium and large organisations in Sri Lanka.

Some of the respondents also believed that they were lacking in understanding of what CAS was. They did not have any knowledge regarding CAS, particularly modern CAS such as ABC (Interview Paragraphs No. 5 and 11). This phenomenon explains why there has been a low CAS adoption rate in Sri Lanka. For example, the majority of respondents expressed that, apart from cultural barriers, the adoption issues come from a lack of infrastructural investment, of research and development, and of training because of insufficient budgets to fully implement CAS. In addition, the majority of respondents indicated that they employed CAS because of the joint existence of coercive, mimetic, and normative pressures within their organisations. Subsequently, these pressures act as triggers to the adoption of CAS. However, since the degree of isomorphism differs between organisations, some respondents were supportive of adopting CAS, while others possess cultural resistance to change.

Supportive respondents indicated that their colleagues and staff have no resistance to adopting CAS (Interview Paragraphs No. 6). This phenomenon is expected to positively trigger the adoption of CAS in Sri Lanka. By contrast, some respondents exhibited a relatively higher level of cultural resistance to change because they were used to working within the existing traditional systems. Making the situation even worse, there are neither regulatory coercive pressures nor institutional mimetic examples for guiding the adoption of CAS (Interview Paragraphs No. 7). Hence, in this case, institutional isomorphism can also act as barriers to the adoption of CAS. Some of the barriers to adopting CAS were cultural, while others were practical. For example, one of the respondents indicated that CAS adoption should initiated by top-level management because of the financial and practical aspects associated with CAS implementation (Interview Paragraphs No. 8).

Overall, the findings indicated that there is evidence of the three processes of institutional isomorphism (coercive, mimetic and normative), which act either as triggers or barriers to adopting CAS. These findings appear to be in line with the earlier literature (DiMaggio and Powell, 1991; Scott, 1995; Kraatz, 1998; Hussain and Hoque, 2002). Previous literature reveals that institutional isomorphism acts only as a cultural trigger (not cultural barrier) for adopting 
CAS. The findings also revealed that in addition to these isomorphic pressures, some indirect influential factors also exist such as culture, economic constraints, and competitive pressures, which have influenced CAS adoption into the organisations.

Apart from 'directed' content analysis, 'summative' content analysis was also applied in this research. In summative content analysis, the presence and meanings of the interview paragraphs are quantified to analyse how many times certain relevant 'codes' or 'themes' appear in relation to the Institutional Isomorphism, Institutional Heterogeneity and Geertz Cultural Theories (Table 3).

Table 3: Summative Content Analysis of the Interview Paragraphs

\begin{tabular}{|l|l|l|l|}
\hline Rank & Codes or Themes & Count & Percentage \\
\hline 1 & Wastage & 51 & $17.17 \%$ \\
\hline 2 & Performance/s & 47 & $15.82 \%$ \\
\hline 3 & Mimetic Pressure & 38 & $12.79 \%$ \\
\hline 4 & Normative Pressures & 32 & $10.77 \%$ \\
\hline 5 & Competition & 31 & $10.44 \%$ \\
\hline 6 & Target/s & 26 & $8.75 \%$ \\
\hline 7 & Efficiency/ies & 21 & $7.07 \%$ \\
\hline 8 & Resist/ance & 21 & $7.07 \%$ \\
\hline 9 & Coercive Pressures & 15 & $5.05 \%$ \\
\hline 10 & Strategy/ies & 10 & $3.37 \%$ \\
\hline 11 & Sophisticated & 5 & $1.68 \%$ \\
\hline & Total & 297 & $100.00 \%$ \\
\hline
\end{tabular}

The themes in Table 3 were guided by the theories, in which organisations compete for superior performance, political power, customers, scarcity of resources, social and economic legitimacy. For example, the themes of 'wastage', 'performance', 'competition', 'target', 'efficiency' and 'strategy' dominated the interview paragraphs, and they accounted for $17.17 \%, 15.82 \%$, $10.44 \%, 8.75 \%, 7.07 \%$ and $3.37 \%$ respectively. This suggests that to achieve persistent superior performance, a firm needs competitive advantages by excelling in multiple aspects such as reducing wastage (first priority), achieving organisational targets and efficiency, as well as undertaking a continuous competitive strategy to carry the firm through competition over time.

Detailed examination of Table 3 reveals that the majority of institutions researched were performance conscious $(15.82 \%)$. They consider they need to maintain their high levels of performance by reducing wastage $(17.17 \%)$ and focusing on organisational targets $(8.75 \%)$. Furthermore, the interview paragraphs reveal the majority of institutions have implemented a wastage avoidance strategy to achieve lower levels of cost-to-income ratios. The cost-toincome ratio is the most important performance indicator in Sri Lanka's banking industry. For example, if a banking institution generated 100 rupees but spent 70 rupees for overall costs, its cost-to-income ratio would be 70. Correspondingly, a lower cost-to-income ratio implies the institution achieved its efficiency by reducing wastage, leading to higher income generation (Interview Paragraphs No. 9). This reduction in wastage could be achieved by adopting modern CAS. 
Furthermore, the findings (Table 3) were dominated by the existence of mimetic pressures as the dominant triggers or barriers to influence Sri Lanka's industry to adopt CAS. For example, the theme of 'mimetic pressures' appears 38 times within the overall interview paragraphs, which accounted for $12.79 \%$ of the overall interview paragraphs. The remaining triggers and barriers were generated from the themes of 'normative and coercive pressures', which accounted for $10.77 \%$ and $5.05 \%$ respectively. Table 3 reiterates the existence of institutional isomorphism in adopting CAS.

In relation to the heterogeneity or RBV theory to Sri Lanka, findings (Table 3) of the interview paragraphs indicate a low frequency of the code of 'sophisticated', only appearing in $1.68 \%$ of the total. This indicates that there are only a small number of companies which have implemented their own unique, sophisticated or advanced accounting systems, comprised mainly of foreign multinationals as opposed to local companies. Along with public sector organisations, the latter are still using simpler or more manual systems such as Microsoft Excel. This finding is logical considering the earlier discussion that indicates the existence of a dual economy in Sri Lanka, in which one part of the economy is characterised by higher levels of efficiency and sophisticated accounting practice, while the other is still dominated by traditional systems and bureaucratic systems. However, through progressive development in Sri Lanka, it is expected that the country's culture will adapt over the long term. Accordingly, more efficient CAS may be implemented, thereby optimising local accounting systems and helping Sri Lanka to achieving a stronger competitive advantage with a rapid transition from dual economy to single economy.

The findings indicate that one of the most prominent reasons for the lack of usage of CAS in organisations in Sri Lanka, especially in the financial sector such as banks, is that the institutions tend to follow the regulatory and accounting aspects of financial reporting per se rather than considering the internal reporting aspects. Therefore, this implies that due to 'coercive pressures', the organisations highly regard the regulations and attempt to meet the requirements provided by the regulatory bodies in the country. Conversely, this also implies that due to regulatory requirements to produce certain types of financial reports, there has been some reluctance to allocate resources to produce other CAS reports to manage the current operations and to measure the effectiveness of the current activities. Correspondingly, the institution relies on the information provided by the financial accounting reports only. This further brings into question the strength of 'coercive pressures' on CAS adoption rather than the financial accounting systems, which are highly confined by the rules and regulations (Interview Paragraphs No. 10). However, it has been identified that when local Sri Lankan organisations merge with international organisations, they would consider implementing such systems, but only as a requirement of the agreement. In other words, the larger multinational organisations can have a similar impact on their subsidiaries or mergers and acquisitions, which could be identified as a trigger for adopting CAS because of 'coercive pressures'.

With regard to 'normative pressures', employing people with experience within the same industry is understood according to the respondents' profiles. Furthermore, organisations would like to implement new systems to maintain their professionalism, however, as far as CAS adoption is concerned, this has not been the case in most of the organisations. Although some organisations have attempted, even with large investments, to implement modern CAS such as activity-based costing systems, the practice and the system have been subsequently abandoned due to the lack of support from the higher management. Also, it seems that the accounting departments struggle in terms of identifying the cost centres, which is a requirement for 
measuring the costs and, therefore, have relied only on past data (Interview Paragraphs No. 11). This is mainly due to frequent changes within the organisations which impact on identifying cost centres and the relevant information required for CAS as well.

From the discussion above, it has been shown that 'mimetic pressures' have been much stronger and also have more influential power than 'normative and coercive pressures'. In addition, culture has been identified as another dominant barrier to adopting CAS. The institutional pressures have created some barriers for the organisations to implement CAS within their organisations. This means that these pressures have again influenced the decision-making process and the strategic response of the management. However, the study has identified that strategic response also has influenced the decision making, hence constructing the argument that an organisation would adopt CAS as per the internal organisational settings as well (Interview Paragraphs No. 12).

Lastly, by discussing CAS (Figure 3) with some respondents, the respondents from organisations in the manufacturing sector indicated that for input measurement, they use the standard method. The method has been widely used in many manufacturing organisations in Sri Lanka. For inventory valuation, they employ simpler CAS, such as the full absorption method (Interview Paragraphs No. 13), although some respondents from service organisations like banks in Sri Lanka are using ABC methods. This finding strengthens the earlier literature of Carenys and Sales (2008), which shown that the full cost or absorption method is more suitable for homogeneous products. For cost accumulation, most manufacturing organisations use the process method but there are a few organisations that use the job order method. The respondents from manufacturing organisations also revealed that they have employed the cost flow method of FIFO while employing periodic recording interval methods. Apart from CAS usage, some garment manufacturing organisations in Sri Lanka today have adopted Japanese systems like lean manufacturing systems (Interview Paragraphs No. 13). In addition, findings from the communicated paragraphs indicate the existence of a dual economy in Sri Lanka, comprised of two separate economic sectors. One sector, which includes foreign multinationals operating in Sri Lanka, has implemented relatively advanced technology with high levels of development, incorporating its own sophisticated and advanced CAS. In contrast, other sectors comprised of local companies are still underdeveloped, in terms of their use of manual or traditional systems such as paper-based record-keeping and manual recording. As such, modern and traditional (poor) systems can be seen to coexist in Sri Lanka. For example, some foreign and major banks have implemented sophisticated ABC systems, while the majority of others, including local banks, are still using manual systems as they develop and integrate them into $\mathrm{ABC}$ systems.

\subsection{Cultural Impact on CAS in view of the Sectors}

As indicated by the interview texts, this group cultural influence has mostly affected the manufacturing sector rather than the service sector, because the manufacturing sector possesses a relatively limited degree of industrial growth in the economy. Most organisations still use simpler manufacturing equipment and systems (Athukorala, 2000; Silva et all., 2016). In addition, compared to the service sector, companies within the manufacturing sector have relatively lower degrees of openness with the outside world in terms of technological systems and progress.

Although some manufacturing firms in Sri Lanka are ahead in implementing modernised CAS, 
in general, the degree of technologies and CAS adoption is relatively low compared to the service sectors, such as finance multinationals and banking companies. This phenomenon is also reflected in the people's attitudes and behaviour within the manufacturing sector (the interview texts no. 1). Compared to the service sector, service firms have a relatively higher degree of openness and higher levels of a marginal propensity to import (MPM) technologies and systems from more advanced economies. Higher levels of the MPM in the service sector indicate that the amount of imports increases with each unit rise in disposable income within the service sector. Service sector companies import more technologies, systems, knowledge, and know-how from abroad. For example, banking and finance multinational companies have started using more sophisticated CAS compared to the manufacturing sector (Seelanatha, 2010). Because of this degree of openness and of higher levels of MPM, the service sector has employed more sophisticated CAS than the manufacturing sector. Correspondingly, the reason for low usage of CAS in the manufacturing sector is the simplicity of its manufacturing practices. Simpler manufacturing practices do not require the use of sophisticated CAS. Simpler CAS, such as breakeven analysis or variable costing systems, is considered adequate. Analogously, the application of institutional homogeneity or institutional heterogeneity is relatively more prevalent within the service sector. Institutional heterogeneity exists more in the service organisations such as banking, finance, and foreign multinationals. Some banking multinationals in Sri Lanka, such as HSBC, have used more sophisticated CAS because the sector has relatively higher MPM of technologies and knowledge transfer from abroad. Apart from MPM, the sector is characterised by a relatively higher degree of openness with the outside world along with relatively higher access to information to justify using advanced CAS. Consequently, banking and finance multinationals in Sri Lanka tend to employ more advanced systems and technologies similar to their counterparts in advanced economies such as the UK, the USA, Germany, etc. Hence they use sophisticated CAS facilitates systems and knowledge transfer from other finance multinationals and banks in Sri Lanka to imitate superior systems. This indicates the existence of institutional isomorphism as well as institutional heterogeneity in Sri Lanka.

\subsection{Theoretical Aspects of the Findings}

The relevant empirical literature is not included within the discussion of the theoretical literature (Section 2) so as to enable an empirical cross-comparison between the findings of the respective studies. The two are deliberately separate as most of the empirical literature examined focuses on the following aspects: (1) the interaction between cultures and accounting in general, or financial accounting statements, such as International Financial Reporting Standards (IFRS), and not between cultures and CAS; (2) the interaction between cultures and accounting practices, not CAS; (3) a developed country context. When considering CAS, empirical literature from developed countries can arguably be considered slightly unconnected owing to the differences between them and developing economies in terms of the degree of industrialisation, standard of living of the economic agents, effective utilisation of production factors, and so on. This section, therefore, proposes to answer the following research question: what is the impact of culture on the adoption of CAS in Sri Lanka in comparison with relevant empirical literature investigating cultural barriers and triggers.

Empirical literature relevant to the subject of culture and CAS has been, thus far, limited to the impacts of cultures on financial reporting (Cieslewicz, 2014). Cieslewicz (2014) does not investigate the impact of culture on CAS. Financial reporting, in general, can be defined as the recording of financial transactions, including sorting, summarising, and presenting the 
information in the form of financial statements in line with IFRS, also known as financial accounting. Although, in this paper, CAS refers more to management accounting systems, rather than financial accounting, some of Cieslewicz's findings (2014) are relevant; for example, the findings reveal that accounting in a particular country is related to the nationally supported accounting institutions, which are influenced by the national culture of a particular country.

In fact, in his results analysis, Cieslewicz (2014) does utilise cultural theories, such as Hofstede (1981, 1984), House, et al. (2004), and Schwartz (1994), which have also been outlined in this paper as the theoretical frameworks employed to compare the national culture with accounting in general. Accordingly, although Cieslewicz's study (2014) relates to financial reporting, his study has been included in the empirical literature reviewed for this paper in the examination of Sri Lanka's adoption of CAS. Applying Cieslewicz's findings (2014) in the context of Sri Lanka, it is evident from this study's interviews that the country's culture of accounting is also influenced by accounting bodies and institutions in the country; for example, the Institute of Chartered Accountants of Sri Lanka (ICASL) is a professional accountancy body which was established under the Institute Of Chartered Accountants Act 1959.

Correspondingly, this paper's findings highlight that the Institute is expected to uphold national standards of accounting and auditing, protecting them from the influences of negative cultural stereotypes and divergent group cultures as indicated in the interview texts. Moreover, Cieslewicz's study (2014) indicates that national economic culture influences institutions, which further influence financial reporting practice. Thus, since the interview findings of this paper reveal the impact of national cultures on the application of CAS, the overall findings should be understood in terms of their strategic and pedagogic implications; that is, institutional adjustments must be made by providing pro-active education and training on CAS in order to address cultural barriers. This strategic training may enhance both conceptual and technical skills to facilitate the adoption of innovative CAS in Sri Lanka (Abayadeera and Watty, 2016; Watty, et al., 2013)

Further comparative empirical literature is provided by Chanegrih's study (2008). The study investigates 65 French manufacturing companies in terms of how national cultures and the macroeconomic context influence the nature of change in management accounting systems. Although the context of the study is the developed economy of France, whose cultural landscape differs greatly from that of Sri Lanka, its proposal that a successful adoption of CAS depends on the degree of resistance to change is useful. This finding is also supported by Ahmad et al. (2012). Regarding resistance to change, Wahyudi (2009) reveals that a system change that violates existing cultural norms fails to have an impact on CAS, as a new system with a technical, efficiency-based accounting system only produces chaotic managerial practices and degrades organisational services as it is argued that the new system alienates staff because of non-acceptance issues. Overall, the conclusion of Wahyudi's research (2009) has strategic implications for adopting and implementing CAS effectively in Sri Lanka.

Another empirical study on the application of more innovative CAS in a developing economy is offered by Liu and Pan (2007). They analyse the application of innovative CAS, such as Activity Based Costing (ABC), in China. Liu and Pan (2007) indicate that the successful adoption of innovative CAS depends on several factors; organisational and cultural setting, along with top management support, is identified as an important success factor. It is expected, therefore, that with the advancement of Sri Lanka's economic development, from the take-off 
stage to the critical mass stage, the country's CAS will also progress considerably (Yongxing et al., 2016).

Other empirical literature on the relationship between cultures and management accounting systems, such as Axa and Greveb (2016) among others, can also be employed for the purposes of cross-comparison. Axa and Greveb's study (2016) focuses on Swedish manufacturing companies to analyse the adoption of more advanced CAS, such as ABC, at the firm level. It draws on two models, discussed in new institutional literature (Love and Cebon, 2008). Axa and Greveb's findings (2016) reveal that the introduction of more innovative CAS, such as $\mathrm{ABC}$, has created a positive environment when the firm is compatible with the systems. On the contrary, within firms that are incompatible, they produce a more negative working environment. Apart from the compatibility aspect, the intensity of the competition could affect the adoption of $\mathrm{ABC}$, as the implementation of an innovative CAS could enhance the firm's compatibility with its organisational process. Applying the literature to the context of Sri Lanka, the interview findings of this study indicate that the majority of respondents agree: firstly, the reasons for not using more advanced CAS are because of compatibility issues with their manufacturing practice. Secondly, other issues concerning optimal CAS implementation in Sri Lanka are due to cultural barriers, in terms of both national and group cultures.

Among the most relevant empirical literature is a study by Erserim (2012), who investigates the relationships between organisational culture, firms' characteristics, firms' perceived environments, and the usage levels of management accounting practices in Turkey. Erserim's findings (2012) reveal that organisational and environmental variables affect the usage level of management accounting practices and, therefore, its CAS. The findings also indicate that there is no relation between perceived competition level, environmental uncertainty, and managerial accounting practices. The findings on the usage level of management accounting practices in Turkey in relation with the organisational environment are partially in line with some of the findings from this study's interviews; however, Erserim's study (2012) analyses organisational cultures without analysing national and group cultures, which may act as barriers to, or indeed triggers for the adoption of CAS.

Iraj, et al. (2007) examine the relationships between Hofstede's (1981, 1984) cultural values and Gray's (1988) accounting values in the developing economy of Iran, during the period 1993 to 2002, by using structural equation modelling. The findings indicate that there are relationships between cultures and accounting values in Iran, and find support for most of Gray's (1988) hypotheses. Iraj, et al. (2007) indicate that inappropriate use of accounting systems are observed in Iran. Although their study analyses the effect of Iran's cultural changes on accounting practice, unlike this paper, it does not examine the national or group cultural barriers to CAS adoption, or its triggers; however, the study is useful as it indicates the existence of cultural impacts on society's values, as well as on accounting systems in general.

At present, CAS in Sri Lanka has undergone rapid development in the face of the standardisation of accounting practices towards economic efficiency. In reality, Sri Lanka has progressed and transformed into a strategically important economic centre of the world because of the development of more robust financial and organisational systems and technologies (Department of National Planning, 2010). However, despite this rapid development, previous research (Subasinghe and Fonseka, 2009) also indicates that the economy is still in its infancy and is struggling with the traditional accounting systems. The contradiction arises due to Sri Lanka economy's experience of a "dual economy" during its economic development stages. 
The dualism materialises because of the existence of two separate economic sectors within one economy; the two sectors are divided by different levels of economic development and technological systems even though they are in the same economy (Singer, 1970; Lewis, 2003; 1954). For example, some sectors, such as the service sector is characterised by higher levels of advanced CAS, as indicated by the progress of finance and banking multinationals in bigger cities in Sri Lanka gearing towards global markets with sophisticated technologies and CAS. In contrast, other sectors, such as agriculture and manufacturing companies, employ simpler work practices because of relatively low growth with a relatively low accountancy literacy rate. The stages of economic development within an economy (from the stage of traditional society, to the preconditions for the take-off stage, to the drive-to-maturity stage, and then to the last stage, the age of high mass consumption) do not happen overnight. To some extent, Sri Lanka has a dualistic economy, in which technologies and systems in some sectors, such as the service sector, including finance multinationals and banking companies are much ahead. Accordingly, in the context of CAS, there has been a coexistence of both modern and traditional CAS in Sri Lanka, as indicated by the interviews. This finding is in line with the literature on the existence of dualism in technologies and systems in developing economies (Boeke, 1953; Lewis, 2003, 1954). Some multinationals have used more advanced CAS with a strong accounting talent base in Sri Lanka as identified in World Bank (2015), while other companies do not employ CAS, or utilise more traditional CAS. On average, based on the primary data collected, the usage of CAS is relatively low in Sri Lanka. However, the findings are limited because of the sample coverage. This qualitative study serves as an initial exploration of the application of CAS in Sri Lanka. Qualitative research does not pretend to capture the whole picture and to propose a generalisation. As some of the respondents discussed, some have surprisingly indicated the usage of more advanced CAS in their companies. This existence of dual accounting systems in the economy was acknowledged in this study.

\section{Summary, Conclusion and Direction of Further Research}

This study critically explores the adoption of CAS using the qualitative research methodology of content analysis. It also examines the factors that facilitate or hinder the adoption of CAS in Sri Lankan service and manufacturing sectors. As qualitative research is used, the limitation of the study is that the knowledge produced might not be generalisable to other countries or other industries. Despite the methodical limitations, however, by studying a limited number of cases in depth in the service and manufacturing sectors, this study is able to explore complex issues of CAS adoption in rich detail phenomena as they are situated and embedded in local contexts of service and manufacturing organisations relating to triggers and barriers regarding adoption of CAS in Sri Lanka.

It was intended that this research made its own contribution by providing further knowledge on aspects of the triggers and barriers to adopting CAS in organisations, not only in a developing country context but also in Sri Lanka as a member country within the SAARC region. Also, this research is distinctive with respect to the theoretical aspects, and institutional isomorphism, institutional heterogeneity and Geertz's cultural theories were employed jointly in this study. The findings indicate the existence of institutional isomorphism (homogeneity) where the adoption of CAS in Sri Lanka was influenced by 'coercive, normative and mimetic pressures' in relation to both cultural triggers and cultural barriers. Partial institutional heterogeneity was observed in Sri Lanka, but heterogeneity is much more apparent in the multinational and more established organisations. The research also found that cultural resistance with group cultures in Sri Lanka is a dominant barrier to the adoption of CAS, which has also been influenced by the group's sluggish approach towards costing. 
Overall, the findings revealed detailed reasons for the lack of usage of CAS in Sri Lanka, such as incompatibility with organisational processes. For example, the use of more innovative CAS requires detailed data measurement across organisational divisions, which is incompatible with the organisational process. Moreover, other factors such as income limitation, costs and training are considered as barriers to the implementation of CAS in Sri Lanka. This study will be useful for facilitating theoretical development, particularly the triggers and barriers for adopting CAS in developing economies. Most innovative CAS, such as ABC, have been designed in advanced countries such as the USA, the UK, France, etc. These developed countries have passed through four stages to reach their current degree of economic development from the earlier stages of traditional society, pre-conditions for take-off, take-off and drive to maturity. This study is expected to guide further theoretical development in designing more innovative CAS for countries during the earlier stages of economic development. For example, by combining CAS with the aspects of imperfect technology and limited industrialisation, innovative CAS can be designed for developing economies.

Moreover, this paper is invaluable for practitioners and policy makers in facilitating the adoption of more modern CAS to enhance the industry's competitive advantage. That is, with proper CAS implementations in the future, Sri Lanka could be a better example for the other countries within the SAARC region, which will help Sri Lanka to gain the benefits of strengthening the trade relations with other Southeast Asian countries and beyond. However, in order to achieve the above goal, Sri Lanka needs to look into further enhancements to its accounting infrastructure, and research and development, to enable the industries to adopt more robust CAS. Hence, not only the practitioners and policy makers but also academia can contribute vastly in this regard because this research could be employed to further explore aspects of the triggers and barriers of adopting more innovative and modern CAS in terms of its theoretical development.

This use of the qualitative research methodology will provide initial insights into problems with the implementation of CAS and will develop potential hypotheses to be used for further quantitative research (Lewis-Beck et al., 2004). The quantitative research methodology can be implemented in the next stage with a larger sample size, which aims at generalising the whole picture of the application of CAS for the purpose of further theoretical development. Hence this qualitative study does not intend to capture Sri Lanka as something that can be generalised to other developing or other developed economies. It aims instead to provide a qualitative snapshot in an initial inquiry.

\section{References:}

Abayadeera, N., \& Watty, K. (2016). Generic skills in accounting education in a developing country: Exploratory evidence from Sri Lanka, Asian Review of Accounting, Vol. 24, Issue 2, pp. 149-170.

Adhikari, P., Kuruppu, C. \& Matilal, S. (2013). Dissemination and institutionalization of public sector accounting reforms in less developed countries: A comparative study of the Nepalese and Sri Lankan central governments. Accounting Forum, Vol. 37, pp.213-230.

Adhikari, P. \& Mellemvik, F. (2010), The adoption of IPSASs in South Asia: A comparative study of seven countries, in Mathew Tsamenyi, Shahzad Uddin (ed.) Research in Accounting 
in Emerging Economies (Research in Accounting in Emerging Economies, Volume 10) Emerald Group Publishing Limited, pp.169 - 199.

Ahmad, K., Gholamreza, H. and Zanyar, S. (2012). The Effect of Accountability on Confidence Level and Resistance to Changing of Accounting System, International Business and Management, Vol. 1, Issue 27.

Aldrich, H. (1979), Organisations and Environments. Englewood Cliffs, NJ: Prentice Hall.

Al-Eqab, M. \& Ismail, N.A. (2011). Contingency factors and accounting information system design in Jordanian companies. IBIMA Business Review, 2011 (2011), Article ID 166128, 1-13, Available from http://www.ibimapublishing.com/journals/IBIMABR/ibimabr.html [Electronically accessed 12th December, 2015.] doi: 10.5171/2011.166128

Alexander, J. Smith, P. and Norton, M. (2011), Interpreting Clifford Geertz Cultural Investigation in the Social Sciences. America: Palgrave Macmillan.

Anthony, R.N. \& Govindarajan, V. (2004). Management Control Systems. (11 ${ }^{\text {th }}$ ed.). New York: McGraw-Hill/Irwin.

Arnould E.J. and Thompson, C.J. (2005), 'Consumer Culture Theory (CCT): Twenty Years of Research', Journal of Consumer Research, 2005, Vol. 31, No 4, pp.868-882.

Ashworth, R., Boyne, G., and Delbridge. (2009), 'Escape from the Iron Cage? Organizational Change and Isomorphic Pressures in the Public Sector', Journal of Public Administration Research and Theory, Vol. 19, No.1, pp.165-187.

Athukorala, P. and Jayasuriya, S. (2012). Economic Policy Shifts in Sri Lanka: the PostConflict Development Challenge. Working Papers in Trade and Development, No. 2012/15, Issue: September, Arndt-Corden Department of Economics, Crawford School of Public Policy, ANU College of Asia and the Pacific, The Australian National University.

Athukorala, P-C. (2000). Manufactured exports and terms of trade of developing countries: Evidence from Sri Lanka, Journal of Development Studies, Vol. 36, Issue 5, pp. 89-104.

Attygalle, K. (2012). Malaysia and Sri Lanka: Dilemmas of the development process. Retrieved November 19, 2013, from http://www.ips.lk/talkingeconomics/2012/04/malaysiaand-sri-lanka-dilemmas-of-the-development-process/

Axa, C. and Greveb, J. (2016). Adoption of management accounting innovations: Organizational culture compatibility and perceived outcomes, Management Accounting Research, Article in Press, Recently available online 21 August 2016 http://dx.doi.org.liverpool.idm.oclc.org/10.1016/j.mar.2016.07.007

Babbie, E. (Eds.). (2008). The Basics of Social Research ( $4^{\text {th }}$ ed.). New York: ThompsonWadsworth.

Barley, S. R. and Tolbert, P. S. (1997). Institutionalization and structuration: studying the links between action and institution. Organization Studies, 18(1), 93-117. 
Barney, J. (2002), Gaining and Sustaining Competitive Advantage. Upper Saddle River, NJ: Prentice Hall.

Barney, J. B. (1986). Strategic factor markets: expectations, luck and business strategy. Management Science, Vol.32, No.10, pp.1231-1241. doi: 10.1287/mnsc.32.10.1231

Barney, J. B. (1991), 'Firm resources and sustained competitive advantage'. Journal of Management, Vol.17, No.1, pp.99-120. doi: 10.1177/014920639101700108

Barney, J. B. (1991), 'Firm Resources and Sustained Competitive Advantage'. Journal of Management, Vol.17, No.1, pp. 99-120.

Barney, J. (1999), 'How a firm's capabilities affect boundary decisions'. Sloan Management Review, Vol.40, No.3, pp.137-145.

Basso, L. F. C., Meirelles, D. S., \& Pace, E. S. U. (2005). The contributions of firm's productive assets to its competitive performance: a resource-based view approach in the software sector. Anais do Encontro Nacional de Economia, Natal, RN, Brasil, 33.

Berg, B. L. (Eds.). (2009). Qualitative Research Methods for the Social Sciences ( $7^{\text {th }}$ ed.). Boston: Pearson Education Inc.

Berg, B.L. \& Lune, H. (Eds.) (2013), Qualitative Research Methods for the Social Sciences ( $8^{\text {th }}$ ed.). Essex: Pearson Education Limited.

Binsardi, A. and Green, J. (2012). Research Methods for Management. Pedagogic Teaching Series, 2, London, Publisher: Northwest Academic Publication, ISBN: 978-1-78233-003-5.

Bjoornenak, T., \& Olson, O. (1999). Unbundling Management Accounting Innovations. Management Accounting Research, Vol.10, pp.325-338.

Boulding, E. (1988). Cultural Perspectives on Development: The Relevance of Sociology and Anthropology, Alternatives: Global, Local, Political, Vol. 14, No. 1, Issue January, pp. 107122.

Boyns, T. \& Edwards, J. (1997). British Cost and Management Accounting Theory and Practice, c.1850-c.1950; Resolved and Unresolved Issues. Business Economic History, Vol.26, No.2, pp.452-462.

Bragg, S. M. (2001). Cost Accounting: A Comprehensive Guide (Hardcover Edition). New York: John Wiley and Sons Inc.

Burke, P. 1997. Varieties of Cultural History, Cambridge, UK, Publisher: Cambridge Policy Press.

Burns, J. and Scapens, R.E. (2000). Conceptualizing management accounting change: an institutional framework. Management Accounting Research, Vol.11, No.1, pp.3-25.

Carenys, J. \& Sales, X. (2008). Costing the Banking Services: A Management Accounting 
Approach. Journal of Money, Investment and Banking, 6, 34-53.

Carmines, E. G. and Zeller, R. A. (1979). Reliability and Validity Assessment, Thousand Oaks, USA, Publisher: SAGE.

Carmines, E. G. and McIver, J. P. (1981). "Reliability and validity assessment", Sage University Paper Series on Quantitative Applications in the Social Sciences, 07-017, Newbury Park, USA, Publisher SAGE

Carpenter, V., \& Feroz, E. (2001). Institutional theory and accounting rule choice: An analysis of four US state governments' decisions to adopt generally accepted accounting principles. Accounting, Organizations and Society, Vol.26, No.7-8, pp.565-596.

Carroll, G.R. and Delacroix, J. (1982), Organisational mortality in the newspaper industries of Argentina and Ireland: an ecological approach, Administrative Science quarterly, Vol. 27, pp.169-98.

Carvalho J. D. C., Gomes, P.S. \& Fernandes, M. J. (2012). The Main Determinants of the Use of the Cost Accounting System in Portuguese Local Government. Financial Accounting and Management, Vol.28, No.3, pp.306-334.

Cavalluzzo, K. S., Ittner, C. D. \& Larcker, D. F. (1998). Competition, efficiency, and cost allocation in government agencies: Evidence from the Federal Reserve System. Journal of Accounting Research, Vol.36, No.1, pp.1-32.

Chanegrih T. (2008). Applying a typology of management accounting change: A research note, Management Accounting Research, Serial Online, Vol. 19, Issue January, pp. 278-285.

Chapman, C., Cooper, D. \& Miller, P. (2009). Linking accounting, organizations and institutions. In C.Chapman, D.Cooper, \& P.Miller (Eds.), Accounting, Organizations and Institutions. Oxford: Oxford University Press.

Cieslewicz, J. K. 2014, Relationships between national economic culture, institutions, and accounting: Implications for IFRS, Critical Perspectives on Accounting, Vol. 25, Issue 6, Edition September, pp. 511-528, Publisher: Elsevier Ltd and Science Direct.

Clarkson, M. E. (1995). A Stakeholder Framework for Analysing and Evaluating Corporate Social Performance. Academy of Management Review. Vol.20, No.1, pp.92-117.

Collins, R. (1979), The credential society, New York: Academic press.

Coyne. T. (1997). "Sampling in qualitative research", Journal of Advanced Nursing, Vol. 26, Issue 3, Edition September, pp. 623-630.

Creswell, J. (1998). Qualitative Inquiry and Research Design: Choosing Among Five Traditions. Thousand Oaks, CA: SAGE Publications Inc.

Dacin, M.T., Goodstein, J. and Scott, W.R. (2002), 'Institutional theory and institutional change; Introduction to the special research forum', Academy of Management Journal, Vol.45, pp.45-57. 
Department of Census and Statistics (DCS) (2012). Census of Population and Housing - 2012 Sri Lanka: Population Tables, Available from http://www.statistics.gov.lk/PopHouSat/CPH2011/Pages/Activities/Reports/FinalReport/Popu lation/FinalPopulation.pdf [Electronically accessed 12th April, 2016.]

Denzin, N.K. and Lincoln, Y.S. (1998). Introduction: Entering the Field of Qualitative Research. Thousand Oaks, CA: SAGE Publications Inc.

Denzin, N. (1978). Sociological Methods, New York, USA, Publisher: McGraw-Hill.

Destradi, S. 2010. India and the Civil War in Sri Lanka: On the Failures of Regional Conflict Management in South Asia, December 23, GIGA Working Paper, No. 154, Issue December, Also available at SSRN: http://ssrn.com/abstract $=1730156 \quad$ or http://dx.doi.org/10.2139/ssrn.1730156

Dierickx, I. and K. Cool (1989). Asset Stock Accumulation and the Sustainability of Competitive Advantage: Reply. Management Science, Vol.35, No.12, pp.1504-1511.

DiMaggio, P.J., \& Powell, W.W., (1991). The New Institutionalism in organisational Analysis. Chicago, IL: university of Chicago Press.

DiMaggio, P.J., \& Powell, W.W., (1983). The iron case revisited: Institutional Isomorphism and collective Rationality in Organisational fields. American Sociological Review, Vol.48, No.2, pp.147-160.

Drury, C. (2015). Management and Cost Accounting, Paperback 9th Edition, London, UK, Publisher: Cengage Learning, ISBN-10: 1408093936.

Eftekhari, A. (2006). Fractal Geometry of Texts. Journal of Quantitative Linguistics, 13(2-3), 177-93.

Erserim, A. (2012). "The Impacts of Organizational Culture, Firm's Characteristics and External Environment of Firms on Management Accounting Practices: An Empirical Research on Industrial Firms in Turkey", Procedia - Social and Behavioral Sciences, Vol. 62, pp. 372376, World Conference on Business, Economics and Management, May 4-6 2016, Antalya, Turkey.

Escobar, L. F. \& Vredenburg, H. (2010), Multinational Oil Companies and the Adoption of Sustainable Development: A Resource-Based and Institutional Theory Interpretation of Adoption Heterogeneity. Journal of Business Ethics, Vol.98, pp.39-65

DOI 10.1007/s10551-010-0534-x

Evans, P. and Bellamy, S. (1995), 'Performance evaluation in the Australian public sector: The role of management and cost accounting control systems', International Journal of Public Sector Management, Vol. 8, No. 6, pp.30 - 38.

Fennell, M.L. (1980), 'The effects of environmental characteristics on the structure of hospital clusters', Administrative Science Quarterly, Vol.25, pp.484-510. 
Finkelstein, S. and Hambrick, D.C. (1996), Strategic Leadership: Top Executives and Their Effects on Organizations. St Paul, MN: West Publishing.

Finney, R., Campbell, N. and Powell, C. (2005), 'Strategies and resources: pathways to success?', Journal of Business Research, Vol. 58, pp. 1721-1729.

Fonseka, K.B.M., Manawaduge, A.S.P.G., \& Senaratne, D.S.N.P. (2005). Management Accounting practices in quoted public companies in Sri Lanka, Colombo: CIMA Sri Lanka division.

Freeman, R. E. (1984), Strategic Management: Stakeholder Approach. Boston: Pitman.

Friedland, R. and Alford, R. R. (1991), 'Bringing society back in: Symbols, practices, and institutional contradictions,' in Walter W. P and DiMaggio, P.J. (eds.), The New Institutionalism in Organizational Analysis. Chicago: University of Chicago Press. pp. 232-263.

Geertz, Clifford (1973). "Thick Description: Toward an Interpretive Theory of Culture", the Interpretation of Cultures: Selected Essays, New-York, USA, Publisher: Basic Books. pp. 330 .

Geiger, D.R. \& Ittner, C. (1996). The influence of funding source and legislative requirements on government cost accounting practices. Accounting Organizatins and Society, Vol.21, No.6, pp.549-567.

Ginzberg, M.J. \& Shillinglaw, G. (1984, November). Information Systems and Cost Control. Paper presented at the Ohio State University Conference on Information Systems and Accounting Education, November 1984. Ohio: Ohio State University.

Ginsberg, A. (1990). Connecting diversification to performance: a sociocognitive approach. Academy of Management Review, Vol.15, No.3, pp.514-535. doi: 10.5465/AMR.1990.4309115

Given, L. M. (2008). The SAGE Encyclopaedia of Qualitative Research Methods. CA: SAGE Publications, Inc.

Glasser, B. and Strauss, A. (1967). The Discovery of Grounded Theory: Strategies for Qualitative Research, Chicago, USA, Publisher: Aldine Publishing Company.

Golden, B.R. \& Zajac, E.J. (2001). When will boards influence strategy? Inclination x Power = Strategic change. Strategic Management Journal, Vol. 22, No. 12, pp. 1087-1111.

Gordon, L. A. \& Miller, D. (1976). A Contingency Framework for the Design of Accounting Information Systems. Accounting, Organizations and Society, Vol.1. No.1, pp.59-69.

Gray, S. J. (1988). Towards a Theory of Cultural Influence on the Development of Accounting Systems Internationally. Abacus, (March), pp.1-15.

Greenwood, R. \& Hinings, B. (1988). ' The Normative Prescription of Organizations', in Zucker, L. G. (eds.), Institutional Patterns and Organizations: Culture and Environment., Cambridge, MA: Ballinger. 
Gupta, P.P., Dirsmith, M. \& Fogarty, T. (1994). Cordination and control in a government agency: Contingency and institutional perspectives on GAO audits. Administrative Science Quarterly, Vol.39, No.2, pp.264-284.

Hamel, G., \& Prahalad, C. K. (1994). Competing for the future. Boston: Harvard Business School Press.

Hansen, D.R., Guan, L., \& Mowen M. M. (2009), Cost Management. Mason,Ohio: SouthWestern Cengage Learning.

Hawley, A. (1968), Human Ecology. in David L. sills (eds.), International Encyclopedia of the Social Sciences. New York: Macmillan. pp.328-37.

Hoffman, A. (2001), From Heresy to Dogma: An Institutional History of Corporate Environmentalism. Stanford, CA: Stanford Business Books.

Hofstede, G. (1984). Culture's Consequences: International Differences in Work-Related Values, $2^{\text {nd }}$ Edition, Beverly Hills, Publisher: SAGE, ISBN 0-8039-1444-X.

Hofstede, G. (2001). Culture's Consequences: comparing values, behaviors, institutions, and organizations across nations, $2^{\text {nd }}$ Edition, Thousand Oaks, USA, Publisher: SAGE.

Hofstede, G. (1991). Cultures and organizations: software of the mind, London, UK, Publisher: McGraw-Hill.

Hooley, G. and Greenley, G. (2005), 'The Resource underpinnings of competitive positions'. Journal of Strategic Marketing, Vol.13, No.2, pp.93-116.

Hopper, T., Tsamenyi, M., Uddin, S. \& Wickramasinghe, D. (2009). Management accounting in less developed countries: what is known and needs knowing. Accounting, Auditing \& Accountability Journal, Vol.22, No.3, pp.469- 514.

Hsieh, H., Hsien, K. and Shannon, S. (2005). Three Approaches to Qualitative Content Analysis. Qualitative Health Research, 15(9), 1277-1288.

Humphrey, C. \& Scapens, R., (1996). Methodological themes - theories and case studies of organizational accounting practices: limitation or liberation?. Accounting Auditing \& Accountability Journal, Vol.9, pp.86-106.

Hussain, M. and Hoque, Z. (2002). Understanding non-financial performance measurement practices in Japanese banks: A new institutional sociology perspective. Accounting, Auditing \& Accountability Journal. 15(2), $162-183$.

Hyndman, N. \& Connolly, C. (2011). Accruals Accounting in the Public Sector: A road not always taken. Management Accounting Research, Vol.22, No.1, pp. 36-45.

Iraj, N., Zahra Dianati, D. and Mohammad S. (2007). The impact of culture on accounting: does Gray's model apply to Iran?, Review of Accounting and Finance, pp. 254, RePEc, 
EBSCOhost, viewed 20 September 2016.

Ismail, N. A. \& King, M. (2005). Firm Performance and AIS Alignment in Malaysian SMEs. International Journal of Accounting Information Systems, Vol.6, No.4, pp.241-259.

Jaggi, B. L. (1973). Accounting systems in developing countries: an assessment. The International Journal of Accounting Education and Research, Vol.9, pp.159-170.

Jarzabkowski, P., \& Searle, R. H. (2005). Harnessing diversity and collective action in the top management team. Long Range Planning, Vol.37, pp. 399-419.

Kali, R. (2003). The city as a giant component: a random graph approach to Zipf's law. Applied Economics Letters, 10(4), 717-20.

Kanter, R. M. (1977). Men and Women of the Corporation. New York: Basic Books.

Karmarkar, U.S., Lederer, P.J. \& Zimmerman, J.L. (1989). Choosing manufacturing production control in cost accounting systems. In R.S. Kaplan (Eds.), Measures of Manufacturing Excellence (pp. 353-396). MA: Harvard Business School Press.

Khandwalla, P. (1972). The effect of different types of competition on the use of management controls. Journal of Accounting Research, Vol.10, No.2, pp.272-285.

Kitching, K., Mashruwala, R. and Pevzner, M. (2016). Culture and Cost Stickiness: A Crosscountry Study, the International Journal of Accounting, Vo. 51, Issue 3, pp. 402-412.

Kraatz, M. S. (1998). Learning by Association? Interorganizational Networks and Adaptation to Environmental Change. Academy of Management Journal. 41(6), 621- 643.

Krishnan, R. (2005). The Effect of Changes in Regulation and Competition on Firms' Demand for Accounting Information. The Accounting Review, Vol.80, No.1, pp.269-287.

Kugiel, P., Cooray, S \& Wickramaratne, T. (2013). Benefits of Regional Integration: What Sri Lanka Can Learn From Poland. Policy Paper, Vol.73, No.25, pp. 1-8.

Kvale, S. (1996). Interviews; An Introduction to Qualitative Research Interviewing. Thousand Oaks, CA: Sage Publications.

Kwan, L.H. (2011), 'Competing globally with cost accounting', University of Tennessee Honors Thesis Projects. http://trace.tennessee.edu/utk_chanhonoproj/1429

Läpple, B. (2015). Current account imbalances in the Eurozone: Is Institutional Heterogeneity to blame?. Master's Programme in Economics, Sweden: Lund University.

Larson, M.S. (1977), The rise of professionalism: A sociological analysis. Berkeley: University of California Press.

Lewis-Beck, M. S., Bryman, B. and Futing Liao, T. F. (2004). The SAGE Encyclopaedia of Social Science Research Methods (Hardcover Edition). London: SAGE Publications, Inc. 
Li, W. (1992). Random Texts Exhibit Zipf's-Law-Like Word Frequency Distribution. IEEE Transactions on Information Theory, 38(6), 1842-45.

Libby, T. \& Waterhouse, J. H. (1996). Predicting change in management accounting systems. Journal of Management Accounting Research, Vol.8, pp.137-150.

Lippman, S. A., \& Rumelt, R. P. (1982). Uncertain imitability. Bell Journal of Economics, Vol.13, No.2, pp.418-438. doi: 10.1057/9781137294678.0712

Liu, L. and Pan, F. (2007). The implementation of Activity-Based Costing in China: An innovation action research approach, British Accounting Review, Serial Online, Vol. 39, Issue 3, Edition September, pp. 249-264.

Lounsbury, M. (2007), 'A Tale of Two Cities: Competing Logics and Practice Variation in the Professionalization of Mutual Funds,' Academy of Management Journal, Vol.50, pp.289-307.

Love, E.G., and Cebon, P. (2008), Meanings on multiple levels: The influence of field level and organisational level meaning systems on diffusion, Journal of Management Studies, Vol.45, pp.239-267.

Lucey, T. (Eds.) (1996). Costing. London: Letts Educational.

Lucey, T. (Eds.) (2008). Costing. London: Letts Educational.

Lyn, Z.J. \& Yu, Z. (2002). Responsibility cost control system in China: a case of management accounting application. Management Accounting Research, Vol.13, pp.447-467.

Mahoney, J. \& Pandian, J. (1992), 'The Resource-Based View within the conversation of strategic management', Strategic Management Journal, Vol. 33, pp. 363-380.

Makadok, R. (2001), 'Toward a synthesis of the resource-based and dynamic-capability views of rent creation', Strategic Management Journal, Vol.22, No.5, pp.387-401.

Martin, J. R. (2014). Management Accounting: Concepts, Techniques and Controversial Issues: MAAW (Management and Accounting Web). Retrieved from http://maaw.info/MAAWTextbookMain.htm

McCloskey, D. 1988. "Thick and Thin Methodologies in the History of Economic Thought", in The Popperian Legacy in Economics, Cambridge, UK, Publisher: Cambridge University Press (CUP).

Meyer, J. W. (1979). The Impact of the Centralization of Educational Funding and Control on State and Local Organizational Governance, Research Report, No. IFG-PR-79-B20, Stanford: Stanford University, California Institute for Research on Educational Finance and Governance.

Meyer, J.W. and Rowan, B. (1977). Institutionalised organisations: formal structure as myth and ceremony. American Journal of Sociology, Vol.83, pp.340-63.

Miles, M.B. and Huberman, M.A. (Eds.). (1994). Qualitative Data Analysis: An Expanded Sourcebook $\left(2^{\text {nd }}\right.$ ed.). Thousand Oaks, CA: Sage Publications.

Miller, P. (1994). Accounting as social and institutional practice: an introduction. In A.G. 
Hopwood and P. Miller (Eds.), Accounting as social and institutional practice. Cambridge: Cambridge University Press.

Morgan, G., Campbell., Crouch, C., Pedersen O. and Whitley, R. (2010). The Oxford Handbook of Comparative Institutional Analysis, Oxford Handbooks in Business and Management, Oxford, UK: Oxford University Press, ISBN-13:9780199233762.

Nagendrakumar, N., Fonseka, M., \& Dissanayake, K. (2015), 'The Development of Public Sector Accounting and Financial Reporting in Sri Lanka', International Journal on Governmental Financial Management - Vol. 15, No 2, pp.70-88.

Nagirikandalage, P. \& Binsardi, B. (2015), Exploring Public Sector Accounting Reforms in an Emerging Economy: A Case of Sri Lanka, in Kelum Jayasinghe, Nirmala D.

Nath, Radiah Othman (ed.) The Public Sector Accounting, Accountability and Auditing in Emerging Economies (Research in Accounting in Emerging Economies, Volume 15) Emerald Group Publishing Limited, pp.51 - 83.

Naranjo-Gil, D., Hartmann, F. and Maas, V. S. (2008). Top Management Team Heterogeneity, Strategic Change and Operational Performance. British Journal of Management, Vol.19: pp.222-234. doi: 10.1111/j.1467-8551.2007.00545.x

Nobes, C. W. (1983). A Judgemental International Classification of Financial Reporting Practices. Journal of Business Finance and Accounting, (Spring), 7-11.

Obara, L.C. \& Ukpai, N.A. (2001). Cost accounting practice in the informal sector of Nigeria (asurvey of eastern business zone). African Administrative Studies, 56, 91-102.

Patton, M. Q. (1980). Qualitative Evaluation Methods, Thousand Oaks, USA, Publisher: SAGE.

Patton, M. (1999). Enhancing the quality and credibility of qualitative analysis, Health Services Research, Vol. 34, Issue 5, Part II, pp. 1189-1208.

Patton, M. (2001). Qualitative Research and Evaluation Methods, 3rd Edition, Thousand Oaks, Publisher: Sage Publications, ISBN-10: 0761919716

Penrose, E. (1959). The theory of the growth of the firm. Oxford: Basil Blackwell.

Peteraf, M. A. (1993). The cornerstones of competitive advantage: a resource-based view. StrategicManagement Journal, Vol.14, No.3, pp.179-191. doi: 10.1002/smj.4250140303

Pettus, M. (2001). The Resource-Based View as a Developmental Growth Process: Evidence from the Deregulated Trucking Industry, Academy of Management Journal, Vol.44, No.4, pp.878-895.

Poole, M.S. \& Van De Ven, A.H. (2004), Handbook of Organizational Change and Innovation. Madison Avenue, New York: Oxford university press. 
Popadiuk, S., Rivera, E. R., \& Bataglia, W. (2014), 'Heterogeneity of Isomorphic Pressures: Intertwining the Resource-Based View and the Neoinstitutional Approach', Brazilian Administration Review (BAR), Vol. 11, No. 4, pp. 455-475.

Prescott, G. L. and Vann, C. E. (2015). The Effects of National Culture on Financial Statement Comparability: A Survey of Research Findings, Journal of Corporate Accounting and Finance (Wiley), Vol. 26, Issue 6, pp. 37-45.

Rumelt, R. P. (1984). 'Towards a strategic theory of the firm.' In Lamb, R. (eds.), Competitive strategic management, Englewood Cliffs, NJ: Prentice-Hall. pp. 556-570.

Rahaman, A.S., Gallhofer, S., Haslam, J., and Lawrence, S. (1997). Public sector accounting and financial management in LDCs: a critical assessment of the literature. Asian Review of Accounting, Vol.5, No.2, pp.38-65.

Ritchie, J. and Lewis, J. (2003). Qualitative Research Practice: A Guide for Social Science Students and Researchers, Thousand Oaks, USA, Publisher: SAGE.

Romney, M. B. and Steinbart, P. J. (2011). Accounting Information Systems, $12^{\text {th }}$ International Edition. New Jersey: Prentice Hall, ISBN-10: 0273754378.

Samuels, J. M. (1990). Accounting for development an alternative Approach. Research in Third World Accounting, Vol.1, pp.67-86.

Scapens, R. W. (1994). Never mind the gap: towards an institutional perspective on management accounting practice. Management Accounting Research, Vol.5, pp.301 - 321.

Scott, W.R. (1995). Institutions and Organisations. London: Sage Publications.

Seelanatha, L. (2010). Market structure, efficiency and performance of banking industry in Sri Lanka, Banks and Bank Systems, Vol. 5, Issue 1, pp. 20-31.

Senaratne, S. \& Gunarathne, A.D.N. (2010). A case of an accountancy study programme in Sri Lanka to improve relevance and quality of undergraduate education: A new dimension on institutional view. Paper presented to the research scholars at the $1^{\text {st }}$ International Conference on business and Information held at University of Kelaniya 2010. Kelaniya, Sri Lanka: University of Kelaniya.

Silva, S.S., Nguyen, T. T., Abery, N. W. and Amarasinghe, U. S. (2016). An evaluation of the role and impacts of alien finfish in Asian inland aquaculture, Journal Aquaculture Research, Vol. 37, Issue 1, pp. 1-17, Publisher: Blackwell Science Ltd.

Smith, C.P. (1992). Motivation and personality: Handbook of thematic content analysis. New York: Cambridge University Press.

Smith, A., Rupp, W. (2002). 'Communication and loyalty among knowledge workers: a resource of the firm theory view', Journal of Knowledge Management, Vol.6, No.3, pp.250261.

Subasinghe, J. \& Fonseka, A.T. (2009). Factors Affecting the Low Adoption of Management 
Accounting Practices in Sri Lankan Business Organizations. Sri Lankan Journal of Management, Vol.14, No.2, pp.95-114.

Thornton, P. (2002), 'The Rise of the Corporation in a Craft Industry: Conflict and Conformity in Institutional Logics,' Academy of Management Journal, Vol. 45, pp. 81-101.

UNDP (United Nations Development Programme) (2012). Sri Lanka Human Development Report 2012: Bridging Regional Disparities for Human Development.Colombo: United Nations Development Programme.

Upchurch, A. (2002). Cost Accounting Principles and Practice. Harlow: Pearson Education Limited.

Violet, W. J. (1983). The Development of International Accounting Standards: An Anthropological Perspective. International Journal of Accounting, pp.1-12.

Vithanage, D. S. (2015), Understanding the Nature and Scope of Patriarchy in Sri Lanka: How Does it Operate in the Institution of Marriage?. Theses in Social Responsibility. Paper 3.

Wahyudi, I. (2009). From physical to accounting control: a study of accounting change resistance, Journal of Accounting and Organizational Change, Vol. 5, Issue 2, pp. 228-238.

Waldron, M. (2005). Overcoming barriers to change in management accounting Systems. The Journal of American Academy of Business, Vol.2, pp.244- 249.

Wallace, R.S.O. (1990). Accounting in LDCs: a review of literature. Research in Third World Accounting, Vol.1, pp.3-54.

Watty, K., Sugahara, S., Abayadeera, N., \& Perera, L. (2013). Developing a Global Model of Accounting Education and Examining IES Compliance in Australia, Japan, and Sri Lanka, Accounting Education, Vol. 22, Issue 5, pp. 502-506.

Yongxing, C., Xiao, W., Li, S., and Yanbo, Z. (2016). "The Construction of Accounting Culture under the Background of Economic Globalization", Conference Journal Proceedings, Annual International Conference on Accounting and Finance, Vol. 1-4. Accessed electronically September 20, 2016 from Business Source Complete, Ipswich, MA

Weerakoon, D. \& Perera, N. (2014). The Role of Sri Lanka in Enhancing

Connectivity between South Asia and Southeast Asia. ADBI Working Paper Series. June 2014, No. 487, pp.1-30.

Wernerfelt, B. (1984). A Resource-Based View of the Firm. Strategic Management Journal, Vol.5, No2, pp 171-180.

Westney, D. E. (1993). 'Institutionalisation Theory and the Multinational Corporation' Iin Ghoshal, S. and. Westney, E. D (eds.), Organization Theory and the Multinational Corporation , New York: Martin's Press.

Winter, S.G. (2003), 'Understanding dynamic capabilities'. Strategic Management Journal, Vol.24, pp.991-995. 
World Bank. (2016). World Development Indicators. Washington, DC.

World Bank (2015). Ending poverty and promoting shared prosperity: A Systematic Country Diagnostic. October 2015.

Yapa, S. \& Ukwatte, S. (2015), The New Public Financial management (NPFM) and Accrual Accounting in Sri Lanka, in Kelum Jayasinghe, Nirmala D. Nath, Radiah Othman (ed.) The Public Sector Accounting, Accountability and Auditing in Emerging Economies (Research in Accounting in Emerging Economies, Volume 15) Emerald Group Publishing Limited, pp.7 50 .

Zaheer, R. (2013). The Economic Performance of SAARC Member Countries. Research on Humanities and Social Sciences. Vol.3, No.5. pp.201-214.

Zipf, G. K. (1949). Human Behavior and the Principle of Least Effort. Upper Saddle River, NJ: Addison-Wesley.

\section{Appendix \\ Selected Interview Paragraphs - Unedited Direct Quotations}

(Full interview paragraphs are available upon request)

Interview Paragraphs No. 1

'...we have learnt not to bother about cost even if you take the lifestyles of the people, whether family life or domestic life, our people are not geared towards cost. The husband is supposed to earn in this culture and the wife does not realise the gravity of the amount that he earns as she would give valid reasons when she spends too much and exceeds the budget but it proves the lack of cost consciousness in the entire process. This is the life that we live in Sri Lanka. I can't say my wife is not educated and she lives in an educated environment but still she also behaves like that. We can't blame them and that's how everyone has grown up. Now if you come to a village, see I am experiencing it now as we have seen that here, this is a village area, our employees are from this village area. We have a big problem right now. Production is not the problem, business is not the problem. But the way of life is the problem...' (Chief Executive Officer in a garment manufacturing company).

'...Apart from being poor it's all because in Sri Lanka we have not been cost conscious. Because other countries since their childhood form the culture itself they get training on costing like 'this is how much you have been given, you should know how to control your budget'. But in Sri Lanka we don't have it or we don't practice like that. In our homes if you call a 15 years of age child and ask him/her how much are you getting monthly or how much are you permitted to spend in this month, that child would say 'I'm not worried about those things' irrespective of being poor or rich. Global marketing concepts are based on these facts like children being able to spend on their own. Yes, they are not earners and they spend other people's money especially 
their parents'. But in Sri Lanka we don't even look at it so our people are not cost conscious. That's one of the biggest problems and we have to have special studies to highlight the cost factor. Today if you happen to walk around and ask any of these individuals what that individual's cost is, he/she might think maybe my salary is the cost. If you go further and say, avoiding the things that they have to consider like looking after parents, etc. and give their individual cost, they will not be able to answer. You will get the same answer if you ask what the cost per minute of this company is. They will not know, they are not interested and they might think that they have to be accountants to understand that. I have tried to speak about these things at our meetings but I have failed because they are not interested, even the senior managers. They just reject it, 'what is cost per minute, we don't want to know', that's the attitude they have...' (Chief Executive Officer in a manufacturing company).

Interview Paragraphs No. 2

'...The management is reluctant to invest more in such system implementations as it needs huge capital. Sometimes we think that the volume of business is varying, I'll give you the example in my businesses. If you take Sri Lanka's total number of vehicles, it is 5 million. Out of these 5 million more than 2.5 million are motor cycles and three wheelers which are not very expensive vehicles to buy. So we manufacture tyres and the cost of the tyres is very low for those types of vehicles. The balance is only less than 2 million cars or motor vehicles and ' lorries' category, in which we are servicing the heavy vehicles, trucks and the light trucks category. Those vehicles are very limited, but we can't do anything for that kind of demand as the market size is small for those categories in Sri Lanka. Also being a small country we are not in a position to look at the international market as well...' (Chief Executive Officer, a tyre manufacturing company).

'...But if you take the overall situation, the volume of the business is what matters the most. So due to that people are very reluctant to invest...' (Chief Executive Officer, a manufacturing company)

Interview Paragraphs No. 3

'...Yes, having a proper Cost Accounting System they can identify the wastages. Since we have the experience of so-called 80 years' experience and now we are changing the minds of the employees. That is, you have to become business managers. Now I am happy about that actually as I can see employees try to look at how to minimise wastage, how to minimise the production defects, etc. How to improve our quality, quality is the no. 1 area where you can differentiate your product. That is the culture I have inbuilt in the employees of the organisation...' (Chief Executive Officer, tyre manufacturing company)

'...The government has published a 'quality year', including quality month, quality day, like that. Due to that we have achieved something in minimising the wastage and the quality management and that is mainly from the cost accounting and management accounting perspectives...' (Chief Executive Officer, tyre manufacturing company)

'... That's again something I agree with it as it's because of the culture actually. If you go to USA or Europe they always maintain that differentiation...' (Chief Executive Officer in a manufacturing company).

(Interview Paragraphs No. 4)

'... Actually all the banks are doing some kind of $\mathrm{ABC}$ but not in a sophisticated manner. There are ways and means like a number of staff or a number of head counts, a number of PCs as 
such, but I would say most of them are at primitive stage in doing that ABC. But as far as NDB is concerned, NDB has a very good system in place...' (Director of Finance at a leading Bank).

'... Now, we are in the process of doing some modifications and developments into the systems to improve the systems with the co-banking activities. We have migrated into a single cobanking system at the bank now. So we are now in the process of developing and talking to the systems via this $\mathrm{ABC}$ system. Therefore, we are trying to integrate the existing systems to the ABC system ...' (Director of Finance at a leading Bank).

'... No, we are not using sophisticated systems for analysis as such. That is, I would say due to the employees, who are using the technology. If you take our in-house built IT systems, I don't think in that context. Also, our information analysis side of the IT is not that so analytical. So the reason is that if you take the corporate finance unit of the whole group itself, also the information technology unit and all the related things are not up to the international level. I am working with the two leading tyre manufacturing organisations in the world. One is a Korean manufacturer and one is an Indian. They are using such sophisticated systems. Every month, they use that kind of mechanism to monitor costs and all the relevant information like for production planning, etc. That's how those international giants use such sophisticated systems. But in Sri Lanka we are not even par with the international level as per the system usage ...' (Chief Executive Officer, a tyre manufacturing company).

'... Cost accounting in the sense, actually we do job costing. So we have to find the total costs for us to make one mould. So, mostly we do it manually using Excel spreadsheets. So as it's a family business, these cost accounting parts actually are handled by myself or my father (the founder of the business) ...' (Chief Operating Officer in a small manufacturing company).

Interview Paragraphs No. 5

'... We don't do cost accounting at all. We always rely on the financial accounting. Nothing much we do in cost accounting. We did a project on cost accounting some time ago, but nothing came into effect after that regarding cost accounting ...' (Chief Accountant, a telecommunication industry).

'... At that project, we hired a project team from the UK to implement ABC. But there were practical issues for us to continue it. Because it was very difficult for us to find the unit costs and cost centres under this method. We couldn't gather data directly from the relevant departments. In addition, we couldn't define the data properly as well ...' (Chief Accountant, a telecommunication industry).

'... We invested so much to implement a cost accounting system and hired professionals from the UK. The UK project team have implemented it. However, we could not continue due to frequent changes. We have not been able to identify and define the cost centres. Additionally, there is the difficulty to find out the information required to calculate the accurate cost per unit, etc ... Since we are a big corporation, we have some sort of monopoly in the market, so we know we make profit. Accordingly the management do not take much consideration of these ..." (Chief Accountant, a telecommunication industry).

'...Also, we failed in activity based costing other than what mentioned earlier because we didn't have proper manuals for the processes. Therefore, it was really difficult for us to adopt the system according to the rapid changes, which have taken place. The user manuals are quite important. We didn't have proper user manuals in place. Actually, this organisation invested a 
lot to implement an activity based costing system. But we couldn't continue it properly due to these difficulties we faced. Also, sometimes the organisation spent more money in order to adopt a new system, but our local project teams wasted most of the money allocated for that particular project just by travelling locally and overseas as well. Also, the company has spent more money on consultancy to implement new systems, but at the end of the day the organisation has not gained anything or the return is not that good. Sometimes, they spent and allocated more money on specific projects and about half way through, they abandoned the project. So much of wasted money is happening indirectly. But our financial accounting side is up to the standard. Even though, the cost accounting processes are not up to the standard, we try to manage the budget somehow. So what we actually do is, we put a profit mark-up and work towards that mark-up ...' (Chief accountant, Telecommunication industry).

Interview Paragraphs No. 6

'... I don't think there was any resistance at all when they implemented this system. It was useful for every employee of the organisation. Employees saw the benefit of this change. Those days, employees had to work late shifts as they had to manually input all the data, etc. Therefore, they really enjoy this new system as it has made our lives easier than before. However, although the finance department is quite happy for the implementation but production department is not happy about it because they have extra workload to update the system as well ...' (Accountant in a garment manufacturing company).

'... They are employees, so they can't resist and they don't have the right to do so, because if they don't like it they have to stay home and we will recruit new people. Also, the majority of them are not permanent staff, mostly work on a contract basis. Permanent staff is very difficult to handle in this business. So it's easy to implement changes as they are on a contract basis ...' (Chief Executive Officer, a construction company)

\section{Interview Paragraphs No. 7}

'... Employees who are in these processes are sometimes not competent. Sometimes, these employees don't like change because they have been working for more than 10 to 15 years in the same organisation. So, sometimes these employees are reluctant to change following the economic and technological situation in the country. Because of those factors, the mechanism we introduced have failed ...' (Chief Executive Officer, a tyre manufacturing company, a subsidiary of a large group of companies).

'... It's a worldwide thing, people don't like change. That is there, but I suppose this concept of cost consciousness should come into the human nature...' (Chief Executive Officer, a garment manufacturing company)

Interview Paragraphs No. 8.

"... that depends on the strategy of the company, whether they are going with the cost leadership or they are going for market penetration or kind of thing. It depends on the overall strategy of our company, but what I would say is, if we are not delivering the required return, if we are not generating the required profit or the return, we can't survive in the market... so we will look into own weaknesses and strengths, also the inefficiencies and we might try to adopt a cost accounting system, if it helps us to compete in the market... " (Director of Finance, a garment manufacturing company).

'... Employees are also mostly very lazy to think extra mile. They just carry on what they have been doing for several years. Also, sometimes, you can't get much support from the employees 
as they think negatively if another employee thinks negatively. Also, if it is beneficial for the organisation, but not for that particular employee, then he or she may oppose the system change...' (Chief Accountant, a telecommunication industry).

'...but sometimes if we have persons like who owns the organisation, sometimes they can use that kind of a systems. So that might be the reason MAS is using this. Amalins (the owner's name) are heavily involved in their businesses. This might be the reason for them to implement sophisticated systems to improve cost efficiency...' (Chief Executive Officer, a garment manufacturing company).

Interview Paragraphs No. 9

'... The banking industry is very worried about the cost-to-income ratio which means cost divided by the net income. A cost-to-income ratio is actually the parameter of banking industry as a whole. Everyone is practising even in their annual planning and budget as they have an internal key performance indicator...' (Director of Finance, a leading bank).

'... But then at the same way, they say that you have to bring down a cost-to-income ratio, from say 55 to 50 , likewise. So if you really analyse the history of some of the banks in Sri Lanka, actually the good examples rely on one of the largest banks in Sri Lanka which is HNB. About 2 to 3 years ago, HNB cost-to-income ratio was 70. This means if they are generating 100 , they are spending the 70 rupees. This happens because of the salaries, systems and all that, there may be so many reasons behind that. So, it could have been their inefficiency, but now today you see that they have brought this cost-to-income ratio down to 55 to 60 . So, it is actually an ideal scenario for Sri Lankan banks; in terms of cost-to-income ratio being around 50 . Because the system is too fragmented. There are so many banks and so many non-financial institutions in the country. They have their own ATMs, their own buildings; they have their own linked telephones, whatever it is. So, the cost is huge in terms of a financial system as a whole. Therefore, I would say if you compare them with those in the developed countries, which have sophisticated systems and the leverage in different terms, the cost-to-income ratio would be around 35 . The foreign banks, you can see, having a 30 to 35 of cost-to-income ratio. So, they have those sophisticated accounting systems and co banking systems abroad. Also, they are serving their other branches around the world too. So, you don't have any overhead costs on that because the mother bank does it for all. So, ideally if you can bring down the overall cost-to-income ratio to 50 , I think that it would be the ideal scenario for the banking industry in Sri Lanka but for the time being. But if you can come down to 40s, that would be really good and that would be benefited the shareholders as well as the other stakeholders...' (Director of Finance, a leading Bank)

Interview Paragraphs No. 10

'... because the bank is basically looking at the kind of regulatory and the accounting aspects of the financial reporting... They mostly follow the ISL FRS IFRS regulations. Also there are some guidelines issued by the central bank of Sri Lanka...' (Director of Finance, a leading Bank)

Interview Paragraphs No. 11

'... At that project, we hired a project team from the UK to implement activity based costing. But there were practical issues for us to continue it. Because it was very difficult for us, to find the unit costs and cost centres under this method. We couldn't gather data directly from the relevant departments and couldn't define the data properly as well. Our business nature was also bit complicated because there were many sectors attached to it. So, we have done an 
internal study. We have identified and defined the cost centres for the time being and have got a tailor made or customised system for us. Also, our higher management changes the structure frequently. Accordingly, the cost centres should be changed. This is practically very difficult to do because it is time wasting as well. In this process of cost accounting, we have to go up to a grass root level to gather relevant data. It is also very difficult to carry out. So, we actually did all the cost calculations based on the past data because it was very difficult to gather current data. Actually, we should do this according to present data. We do sort of activity based costing by using past data because we face difficulties in gathering required data from the grass root level. Also, the most difficult thing is to find the non-financial data... ' (Chief Accountant, a telecommunication industry).

Interview Paragraphs No. 12

'... Also, our higher management changes the structure frequently. Accordingly, the cost centres should be changed. This is practically very difficult to do because it is time wasting as well ... ' (Chief Accountant, telecommunication industry).

'... I think the cost management initiative should be taken by the finance department. Also the cost management should be the CEO's vision. So CEO should drive this, because I think no one volunteer would do this kind of cost management except the higher management. There should be a top down approach in terms of managing costs. So, if the CEO and CFO are taking the control over the cost management, we can easily build down to the other units and departments as well. So we can introduce changes quite smoothly...' (Director of Finance at a leading bank).

'... but definitely if you invest something, you will not get immediate return. Therefore, I will struggle for the next two years. Struggling in the sense that I will not make losses but the profitability would come down and then I would actually be under pressures from the higher management. So, that can actually be one reason for me not to keen on suggesting such ideas of implementing better systems even if we are capable to implement such systems as an organisation...' (General Manager, a tyre manufacturing company)

'... Hardly, any company would take that challenge to invest money to implement better systems. The only thing is that if the management is different. The board of directors or the higher management always want developments in the sense of a bottom line. Management is employees, who manage the organisation. So, they only look at the very short period of time, maximum of 3 years. But sometimes, if we have people, who own the organisation, sometimes they could use that kind of systems. So, that might be the reason MAS is using this. Amalins (the owners' name) are heavily involved in these businesses. That might be the reason for them to implement sophisticated systems to improve cost efficiency ...' (Chief Executive Officer, a garment manufacturing company)

'... One reason is that the higher management is not prepared to implement it. Even though, they implement it, they go back to the previous methods again. There were CEOs, who killed this industry and moved to different industries. Some actually created bad images to the country and somehow got away with it due to political backing ... '(Chief Executive Officer, a garment manufacturing company)

'... Also as we have monopoly power in this telecommunication market. The management is not quite ready to invest in such sophisticated systems. But, this would be advantageous for us to identify profitable products and service that we offer to the customers. But, since it's 
monopoly, the higher management believes that it's going to be profitable anyhow... ' (Chief Accountant, a telecommunication industry)

'Sometimes, the higher management just tries to implement something but does not consider the benefits to the whole organisation, but the management increases their performances by showing that they are doing something new.' (Accountant, a garment manufacturing company)

Interview Paragraphs No. 13

'It's the Enterprise Resource Planning (ERP) system. But the batch costing, we do on Excel spreadsheets. All the data like material costs, etc. are input to the ERP system. To calculate the batch wise costing, we use Excel spreadsheets. So the relevant data are exported to Excel from this ERP system. But, there are sometimes issues arising, like there are occasions, where they haven't updated the relevant information or have not inputted the data into the system even after the batch had been produced. So, we need to run the system several times to get the updated data to calculate batch costing. We call 'activity report' for which we calculate the batch costing. We do absorption costing ... ' (Accountant, a garment manufacturing company)

'... For input measurement, we basically use the standard method in Sri Lanka. I think this is widely used in many organisations as well. As a manufacturing organisation, for inventory valuation, we use the full absorption method. But I know there are service organisations like banks in Sri Lanka who are trying to adopt activity based costing method nowadays. For cost accumulation, we used the process method but there are organisations in the industry that use the job order method as well. According to this diagram, which you are showing to me now, I would say the cost flow method that we use is FIFO and the recording interval method that we follow is periodic. Also, as a garment manufacturing organisation in Sri Lanka nowadays, we try to adopt the Japanese systems like lean manufacturing ...' (Chief Accountant, a garment manufacturing company)

'... if you take Japanese systems, they have originated the lean manufacturing systems, today China is adopting lean manufacturing systems without knowing that they are doing lean manufacturing, so that's their effort. Although we are adopting these things but Sri Lanka has failed...' (Chief Executive Officer, a garment manufacturing company).

'...We are now moving towards lean manufacturing systems, which have been introduced firstly to manufacturing production. But we don't have a proper system to assess the impact of this new system change. So what the management do is, they take the past data before introducing the lean method and compare the current production with past information...' (Accountant, a garment manufacturing company) 